\title{
No. 16
}

FEBRERO DE 2017

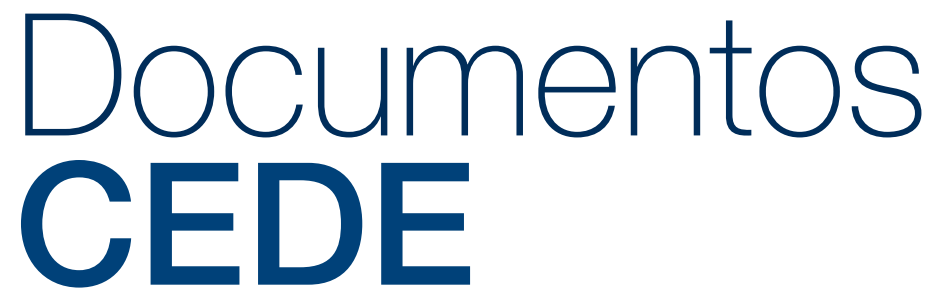

ISSN 1657-7191 Edición electrónica.

When Ignorance is Bliss: Theory and Experiment on Collective Learning

Boris Ginzburg José-Alberto Guerra 


\section{CEDE}

D1)

Facultad de Economía

Serie Documentos Cede, 2017-16

ISSN 1657-7191 Edición electrónica.

Febrero de 2017

(C) 2017, Universidad de los Andes, Facultad de Economía, CEDE. Calle 19A No. 1 - 37 Este, Bloque W.

Bogotá, D. C., Colombia Teléfonos: 3394949- 3394999, extensiones 2400, 2049, 3233

infocede@uniandes.edu.co

http://economia.uniandes.edu.co

Impreso en Colombia - Printed in Colombia

La serie de Documentos de Trabajo CEDE se circula con propósitos de discusión y divulgación. Los artículos no han sido evaluados por pares ni sujetos a ningún tipo de evaluación formal por parte del equipo de trabajo del CEDE.

El contenido de la presente publicación se encuentra protegido por las normas internacionales y nacionales vigentes sobre propiedad intelectual, por tanto su utilización, reproducción, comunicación pública, transformación, distribución, alquiler, préstamo público e importación, total o parcial, en todo o en parte, en formato impreso, digital o en cualquier formato conocido o por conocer, se encuentran prohibidos, y sólo serán lícitos en la medida en que se cuente con la autorización previa y expresa por escrito del autor o titular. Las limitaciones y excepciones al Derecho de Autor, sólo serán aplicables en la medida en que se den dentro de los denominados Usos Honrados (Fair use), estén previa y expresamente establecidas, no causen un grave e injustificado perjuicio a los intereses legítimos del autor o titular, y no atenten contra la normal explotación de la obra.

Universidad de los Andes | Vigilada Mineducación

Reconocimiento como Universidad: Decreto 1297 del 30 de mayo de 1964. Reconocimiento personería jurídica: Resolución 28 del 23 de febrero de 1949 Minjusticia. 


\title{
When Ignorance is Bliss: Theory and Experiment on Collective Learning*
}

\author{
Boris Ginzburg $^{* *}$ and José-Alberto Guerra ${ }^{* * *}$
}

\begin{abstract}
When do groups and societies choose to be uninformed? We study a committee that needs to vote on a reform which will give every member a private statedependent payoff. The committee can vote to learn the state at no cost. We show that the committee decides not to learn the state when preferences are more fractionalised on the state-relevant dimension than on the state-irrelevant dimension. Hence, decisions on divisive issues are likely to be made in haste, and heterogeneous societies tend to seek less information. A simple laboratory experiment confirms key results.
\end{abstract}

JEL Classification Numbers: C72, C92, D71, D72, D83.

Keywords: voting, collective learning, reform adoption, information acquisition, laboratory experiment

${ }^{*}$ We are grateful to V Bhaskar for valuable advice, and to Antonio Cabrales, Amanda Friedenberg, Philippe Jehiel, Christian Krestel, Roger Myerson, Santiago Oliveros, Nikita Roketskiy, Syon Bhanot, Andres Zambrano and audiences in Barcelona, Bilbao, Bogota, Budapest, Edinburgh, Lindau, Lisbon, London, Madrid, Moscow, Palma de Mallorca, Riga, Santiago, Stony Brook, Toulouse, and Tucson for helpful comments. Amalia Rodríguez and Andrés Cárdenas provided very able research assistance. We thank the financial support from Central Bank of Colombia (grant 3754), Spanish Ministry of the Economy (grant MDM 2014-0431), and Comunidad de Madrid (grant S2015/HUM-3444). We thank Universidad del Rosario for hosting the experiment.

** Department of Economics, Universidad Carlos III de Madrid. Email: boris.ginzburg@uc3m.es

${ }^{* * *}$ Department of Economics, Universidad de los Andes. Email: ja.guerra@uniandes.edu.co 


\title{
Cuando la Ignorancia es Dicha: Teoría y Experimento sobre Aprendizaje Colectivo§
}

\author{
Boris Ginzburg* y José-Alberto Guerra
}

\begin{abstract}
¿Cuándo los grupos y las sociedades deciden no estar informados? Estudiamos un comité que necesita votar sobre una reforma que dará a cada miembro un pago privado dependiente del estado. El comité puede votar por aprender el estado sin costo alguno. Mostramos que el comité decide no aprender el estado cuando las preferencias son más fraccionadas en la dimensión relevante del estado que en la dimensión irrelevante del estado. Por lo tanto, es probable que las decisiones sobre cuestiones divisivas se hagan con prisa, y las sociedades heterogéneas tiendan a buscar menos información. Un experimento de laboratorio confirma los resultados teóricos claves.
\end{abstract}

Números de Clasificación JEL: C72, C92, D71, D72, D83.

Palabras Clave: votación, aprendizaje colectivo, adopción de reformas, adquisición de información, experimento de laboratorio

\footnotetext{
$\S$ Agradecemos a V Bhaskar por sus valiosos consejos, y a Antonio Cabrales, Amanda Friedenberg, Philippe Jehiel, Christian Krestel, Roger Myerson, Santiago Oliveros, Nikita Roketskiy, Syon Bhanot, Andres Zambrano y audiencias en Barcelona, Bilbao, Bogota, Budapest, Edinburgh, Lindau, Lisbon, London, Madrid, Moscow, Palma de Mallorca, Riga, Santiago, Stony Brook, Toulouse, y Tucson por comentarios pertinentes. Amalia Rodríguez y Andrés Cárdenas fueron muy buenos asistentes de investigación. Agradecemos el apoyo financiero del Banco de la República de Colombia (Proyecto 3754), Ministerio Español de Economía (grant MDM 2014-0431), y Comunidad de Madrid (grant S2015/HUM3444). Agradecemos a la Universidad del Rosario por prestar su laboratorio para correr los experimentos.

*Departmento de Economía, Universidad Carlos III de Madrid. Email: boris.ginzburg@uc3m.es

『Facultad de Economía, Universidad de los Andes. Email: ja.guerra@uniandes.edu.co
} 


\section{Introduction}

The outcomes of reforms and other collective decisions are often uncertain when the decision is being made. For example, trade liberalization can help some industries while hurting other - but it is not always evident in advance which industry will gain and which will lose. A reform of higher education induce prospective students to reallocate between degree programs, but the direction of change may be uncertain. Allocation of research funding, adoption of environmental regulations, investment in infrastructure projects, and academic hiring are some of the other examples of decisions with uncertain outcomes.

The common feature of many of these scenarios is that individual members of the decision-making body know their payoffs under each of these outcomes. But the outcomes themselves are unknown. Yet the decision-making body can vote to learn this information collectively. For instance, they can decide to delay the decision on the reform until more information becomes available. A pilot project can be implemented to learn about the effects of the reform. A study may be commissioned before the reform is put to vote. But when will the group choose to learn, and when will it choose to vote "in ignorance"?

This paper addresses the above question by modeling, and experimentally testing, the decision of a committee that needs to vote whether to adopt a reform. If adopted, the reform will give every member a private payoff which depends on a binary state of the world. Individual payoffs in each state are commonly known, but the state is initially unknown. Prior to voting on the reform, the committee can vote to learn the state, at no cost.

Will the committee ever vote against learning? It is easy to see that if committee members have similar preferences, they will weakly prefer to learn the state before making the decision. But when preferences differ, this need not be the case, as the following example shows. Let the committee consist of three members, called Anna, Bob, and Claire. Suppose decisions are made by simple majority voting, and the two states are equally likely. If the reform is rejected, each member receives a payoff of zero. If the reform is approved, the payoffs of its members are as follows:

\begin{tabular}{ccc}
\hline & Payoff in the first state & Payoff in the second state \\
\hline Anna & 3 & -1 \\
Bob & -1 & 3 \\
Claire & -3 & -3 \\
\hline
\end{tabular}

If the committee has voted to learn the state before deciding on the reform, then in every state the reform is rejected by a majority of voters, giving each of them a payoff of zero. If the committee has voted not to learn the state, then Anna and Bob vote for the reform, and in expectation each of them receives a positive payoff. Thus, in expectation, Anna and Bob each receive a higher payoff if information is not acquired than if it is. 
Accordingly, they vote against learning the state - and since they constitute a majority, the committee chooses not to acquire information. We can thus say that the committee has a collective preference for ignorance.

The key factor behind this outcome is that the reform is rejected when either state is revealed. Ex ante, however, the reform is adopted. Thus, information moves the collective decision away from the one that the majority initially prefers - so the majority votes against acquiring information. This logic underlies many of the theoretical results in the paper that are replicated by the experimental evidence.

In particular, this logic leads to the paper's basic theoretical result: a simple condition on the distributions of individual payoffs across voters that is necessary and sufficient for the committee to have a preference for ignorance. It turns out that a collective preference for ignorance exists whenever individual preferences of committee members are sufficiently heterogeneous. Specifically, ignorance is a collective decision whenever the committee is more fractionalised on the state-relevant dimension than on the stateirrelevant dimension. This implies that decisions on divisive issues ${ }^{1}$ are likely to be made without careful consideration of their consequences.

More generally, the paper suggests that fractionalisation and preference heterogeneity have an important effect on collective decisions. Heterogeneous groups and societies are likely to make decisions in haste, to seek less expert advice, to enact or reject reforms without analyzing their potential effects, and to have less public debate on proposed policies. In this way, the approach adds to the large literature that examines the implications of social fractionalisation and diversity ${ }^{2}$. The result also matches some of the existing empirical evidence from political science (Anderson and Paskeviciute, 2006) and organizational psychology (Mannix and Neale, 2005), which suggests that greater heterogeneity is associated with lower engagement in public discussion and lower level of information exchange.

From a normative point of view, the paper examines the effect of a rule that enforces learning regardless of the committee's decision. Such a rule is optimal when there is a minority of voters with a large stake in the collective decision. Hence, commitment to transparency can be a mechanism of protecting minorities.

We test the main theoretical results in a laboratory setting. Subjects are grouped into three-member committees. They are informed that there are two possible states of the world. Each committee is asked to choose between two options. One option gives each subject a safe payoff, while the other gives each of them a payoff that depends on the state. State-dependent payoffs are assigned randomly, and are commonly known. Before voting on the option, the committee votes on whether to learn the state. In line with theoretical predictions, we find that committees are substantially less likely to acquire information

\footnotetext{
${ }^{1}$ Divisive in the sense that there is no general agreement on which outcome is preferred to the other.

${ }^{2}$ See Mauro (1995), Easterly and Levine (1997), Collier (2001), Alesina et al. (2003).
} 
when individual preferences are more fractionalised on the state-relevant dimension than on the state-irrelevant dimension. Specifically, in the former case committees acquire information 30-35 percentage points less often (depending on the treatment) that in the former case. The result holds in a setup when information is costless as well as when there is a slight cost of acquiring it; it also holds for different priors. Individual voting behaviour tends to be in line with theoretical predictions as well. Furthermore, individuals with more experience in decision-making bodies, or with greater level of strategic competence, are more likely to vote as the model predicts, which presents some evidence for external validity of the model.

The rest of the paper is organized as follows. Section 2 describes the model. Section 3 presents the theoretical results, including the conditions under which the committee votes for ignorance, and the effects of a commitment to learning. Section 4 describes the design of the experiment. The results of the experiment are described in Section 5. Finally, Section 6 concludes.

\subsection{Related Literature}

Several papers have previously looked at collective decisions to acquire information. Strulovici (2010) examines the problem facing a committee that, in every round, needs to choose between a safe option and a risky option. Committee members do not initially know their preferences, but they can learn them when the risky option is exercised. The decision to exercise the risky option is reversible. The paper shows that the level of learning generally is inefficiently low. Fernandez and Rodrik (1991) use a similar approach to examine a collective decision to adopt a risky reform. They show that when voters are uncertain about their payoffs from the reform, a welfare-enhancing reform may be reversed $^{3}$. Messner and Polborn (2012) similarly consider a choice between delaying the decision (and thus learning some information) and adopting a proposal early. They show that a supermajority rule can lead to less conservative decisions than a simple majority rule. Godefroy and Perez-Richet (2013) develop a model in which a committee votes whether to place a proposal on the agenda before voting on the proposal itself. The paper shows that a more restrictive agenda selection rule can make voters more conservative, while a more conservative decision rule has the opposite effect.

A key difference between this paper and those described above is that in the latter, voters do not know their preferences and can collectively decide to learn them; ex ante, the voters are identical. In contrast, in this paper voters differ in their ex ante preferences, which are commonly known. This is a key feature of the model, since it makes it possible to determine preference distributions under which the committee votes against learning. Furthermore, in contrast to Strulovici as well as Fernandez and Rodrik, in this paper

\footnotetext{
${ }^{3}$ Dewatripont and Roland (1995) also look at adoption of reforms with uncertain outcomes.
} 
learning is the result of exercising a safe option, while exercising the risky option (adopting the reform without learning) is irreversible and ends the game.

Lizzeri and Yariv (2013) look at a jury that faces a choice in every round between continuing to gather information and making a decision. They find that greater heterogeneity leads to more information acquisition. Unlike this paper, they restrict attention to a setting in which jury members have preferences that are monotone in the state everyone prefers to acquit an innocent defendant and to convict a guilty one. In such a setting, information will always be acquired if it is costless; in Lizzeri and Yariv the decision to stop gathering information is driven by the fact that it is costly. Unlike Lizzeri and Yariv, we look at cases in which voters are heterogeneous in the sense that their preferences are not necessarily monotone in the state. It is precisely this heterogeneity that drives the vote against acquiring information even when doing it is costless.

This paper is also related to the literature on collective search (Albrecht et al., 2010; Compte and Jehiel, 2010; Moldovanu and Shi, 2013). In that literature, a committee must decide between adopting the current alternative and continuing to search for more alternatives. Continuing the search makes the committee more informed, but it also means foregoing the payoff from the alternative in the current round. In this paper, on the other hand, deciding to learn the state before voting on the reform does not entail any change in payoffs from the reform. The decision to stay uninformed is driven instead by the effect of information on the collective decision.

A number of papers have looked at collective decision-making in an experimental setup (see Palfrey (2013) for a comprehensive survey). Guarnaschelli et al. (2000) examine an information aggregation problem analogous to the one studied by Feddersen and Pesendorfer (1998). In an experiment where learning is not possible, Cason and Mui (2005) investigate the impact of uncertainty on the benefits of a reform on the likelihood of its adoption. They find that uncertainty reduces the incidence of reform. When costly political participation is introduced, subjects' behavior is better explained by a quantile response model. Plott and Llewellyn (2015) evaluate a committee that deliberates on a decision. Committee members' preferences depend on an unknown state of nature. Two experts, who have opposing preferences regarding the committee's decision, are informed about the state, and can provide recommendations to the committee at the beginning of the deliberation. The paper suggests that, although experts do not generally tell the truth, the committee acts as if knowing what experts know.

Exploiting individual preference heterogeneity, Goeree and Yariv (2011) experimentally study the effects of deliberation on collective decisions. Unlike this paper, in their analysis the group does not vote whether or not to learn the state; instead, group members can communicate. Without communication, different voting rules generate statistically different outcomes. Introducing deliberation reduces these differences and efficiency increases.

The fact that public information can reduce individual expected payoffs has been 
noticed by Hirshleifer (1971), who showed that risk-averse individuals may be worse off when information eliminates insurance opportunities. Gersbach (1991) and Gersbach (2000) show a similar effect in a voting framework. Unlike these papers, we focus on a collective decision to acquire information, which can be both positive and negative when acquiring information is socially optimal as well as when it is not.

A number of papers have looked at information aggregation through voting (AustenSmith and Banks, 1996; Feddersen and Pesendorfer 1997; Goertz and Maniquet, 2011; Bouton and Castanheira, 2012; Bhattacharya, 2013). In that literature, information is dispersed among voters, each of whom has an imperfect signal about the state. Under certain conditions, voting can aggregate information - that is, the outcome of the voting is the same as if all private signals were made public. In contrast, in this paper there is no private information, and acquiring a public signal about the state is a matter of collective choice.

More broadly, this paper is also related to research on acquisition of private information by individual members of committees ${ }^{4}$, as well as to studies of information exchange among committee members ${ }^{5}$. Also related is the literature on private information acquisition in coordination games ${ }^{6}$.

\section{Model}

A committee $I$ comprising an odd number of members needs to decide between two alternatives, called "status quo" and "reform". Each alternative gives every member a utility that depends on a binary state of the world $\omega \in\{X, Y\}$. For a member $i \in I$, the difference between her utility from the reform and from the status quo is $x_{i}$ if the state is $X$ and $y_{i}$ if the state is $Y$. These utilities can be positive or negative. Let $x \equiv\left(x_{1}, x_{2}, \ldots\right)$ and $y \equiv\left(y_{1}, y_{2}, \ldots\right)$ denote vectors of individual state-dependent payoff differences. We will normalise each member's payoff from the status quo to zero - thus, $x_{i}$ and $y_{i}$ are equal to individual utilities from the reform. The state is initially unknown. Let $\pi$ be the probability that the state is $X$. Aside from the state, all aspects of the game (including individual payoffs) are common knowledge.

Before deciding between the reform and the status quo, the committee choose whether to learn the state. If they choose to do so, the state becomes common knowledge, and members then vote on whether to adopt the reform. If they choose not to learn the state, the committee has to vote on the reform "in ignorance".

All decisions (whether to learn the state, and whether to approve the reform) are

\footnotetext{
${ }^{4}$ Persico (2004); Gerardi and Yariv (2008); Gershkov and Szentes (2009); Gersbach and Hahn (2012); Oliveros (2013).

${ }^{5}$ Visser and Swank (2007); Gerardi and Yariv (2007).

${ }^{6}$ Dewan and Myatt (2008); Hellwig and Veldkamp (2009); Myatt and Wallace (2012).
} 
made by majority voting. Member cast their votes simultaneously, and the option with the largest number of votes is selected. To avoid trivial equilibria we will, in line with much of the literature on voting games, only consider equilibria in which weakly dominated strategies are eliminated. Thus, every agent votes sincerely, as if she were pivotal.

\section{Results}

\subsection{Preference for Ignorance}

When the reform is put to vote, each member votes in favour of the reform if and only if her expected payoff from the reform is positive. Equilibrium strategies then determine a function $g: \mathbb{R}^{I} \rightarrow\{0,1\}$ that maps the vector of expected payoffs from adopting the reform to the collective decision on the reform, where 1 denotes a positive decision (adopting the reform). For a given vector of expected payoffs, the function $g(\cdot)$ takes a value of 1 if and only if the share of positive elements in that vector is at least 0.5 . In other words, $g(\cdot)$ indicates whether the median of a vector is positive.

Note that $g(\cdot)$ has the following properties, which will be useful in the subsequent analysis:

1. For any scalar $\lambda>0$, and any payoff vector $z \in \mathbb{R}^{I}, g(z)=g(\lambda z)$.

2. For any payoff vector $z \in \mathbb{R}^{I}$ that does not contain zeroes, $g(-z)=1-g(z)$.

The first property says that the collective decision is invariant to rescaling of payoffs. The second says that for a simple majority rule, if the reform is adopted under a given vector of expected payoffs, then it is rejected under a vector of opposite expected payoffs.

Suppose the committee votes to learn the state. With probability $\pi$ the state turns out to be $X$. If the reform is then adopted, each voter $i \in I$ receives a payoff $x_{i}$. Thus the reform is adopted if and only if $g(x)=1$. Similarly, with probability $1-\pi$ the state turns out to be $Y$, and the reform is adopted (giving each voter $i$ a payoff $y_{i}$ ) whenever $g(y)=1$. Thus, if the collective decision is to learn the state, the expected payoff of agent $i$ equals

$$
\pi x_{i} g(x)+(1-\pi) y_{i} g(y)
$$

If instead the committee decides not to learn the state, then the reform, if selected, will give each voter an expected payoff of $\pi x_{i}+[1-\pi] y_{i}$. The reform is then approved whenever $g(\pi x+[1-\pi] y)=1$. Hence, voter $i$ 's expected payoff equals

$$
\left(\pi x_{i}+[1-\pi] y_{i}\right) g(\pi x+[1-\pi] y)
$$

When deciding whether to vote for learning the state, each voter compares her expected payoffs with and without information. Let $v_{i}$ be the value of ignorance for voter $i$ - that 
is, the gain in $i$ 's expected payoff from voting on the reform without information instead of learning the state prior to voting. Then $v_{i}$ equals

$$
\left(\pi x_{i}+[1-\pi] y_{i}\right) g(\pi x+[1-\pi] y)-\pi x_{i} g(x)-(1-\pi) y_{i} g(y)
$$

Voter $i$ votes to learn the state if $v_{i}<0$, and votes against learning the state if $v_{i}>0$. Then the committee collectively chooses to learn the state whenever $g(v)=0$, where $v \equiv\left(v_{i}\right)_{i \in I}$ is the vector of net gains from ignorance for all agents. When $g(v)=1$, the committee collectively chooses to vote on the reform without learning the state - in other words, the committee has a collective preference for ignorance.

Note that it is possible for voters to be indifferent between some of the decisions. In particular, when $g(x)=g(y)=g(\pi x+[1-\pi] y)$ - i.e. when the committee votes on the reform the same way in either state and also ex ante - then $v_{i}=0$ for all $i \in I$. In that case all voters are indifferent between learning and not learning the state. Therefore, the subsequent analysis will distinguish between a weak and a strict collective preference for ignorance. In particular, a weak preference for ignorance is equivalent to assuming that information has a small cost - small in the sense that it is smaller than any payoff difference that enters a voter's utility calculations.

With this distinction in mind, we can, for the case when decisions are made by a simple majority rule, derive a simple necessary and sufficient condition for the committee to decide against learning the state.

Proposition 1 For any $\pi \in(0,1)$, the committee has a weak preference for ignorance if and only if $g(x)=g(y)$. Furthermore, the committee has a strict preference for ignorance if and only if $g(x)=g(y) \neq g(\pi x+[1-\pi] y)$.

Proof. See Appendix.

In words, the committee weakly prefers making a decision without information if and only if the collective decision on the reform is the same after either state is revealed. The committee strictly prefers not acquiring information if and only if the collective decision on the reform is the same after either state is revealed, while also being different from the collective decision on the reform made without information. ${ }^{7}$

Intuitively, the committee wants to learn the state when knowing the state affects its collective decision on the reform. If the decision is the same in both states, two cases

\footnotetext{
${ }^{7}$ One could interpret the information decision as individuals facing a two-stage lottery and voting whether they want uncertainty to be resolved in the first stage. Segal (1987) points out that a decision maker failing to reduce this compound lottery can be interpreted as ambiguity-averse (i.e. a dislike of uncertainty about probability distributions over outcomes). Our model is then a model of ambiguity-neutral subjects under the smooth ambiguity preference framework (Klibanoff et al., 2005). The experimental literature (Machina and Siniscalchi, 2014; Halevy, 2007) suggests individuals are either ambiguity-neutral or ambiguity-averse. We will come back to this discussion in our results section.
} 
are possible. First, that decision can also be the same as the decision on the reform in ignorance - in this case, information has no effect on the outcome, and the committee weakly prefers not to have it. Second, the decisions in both states can be be different from the decision that is preferred by the majority ex ante. In this case, information moves the collective decision on the reform away from the decision that was optimal ex ante thus, the majority will prefer not to have that information. This is what happened in the example mentioned in the Introduction.

Proposition 1 implies the following result:

Corrollary 1 Under a simple majority rule, whenever there is a strict preference for ignorance, the preferred decision of the median voter in either state will never be implemented.

Proof. Strict preference for ignorance exists when the median voter's preferred decision in either state is different from the ex ante decision. But under a strict preference for ignorance, the ex ante decision on the reform will be the one that the group will implement.

This result is, of course, different from what the median voter theorem suggests. When the committee can endogenously determine whether they want to acquire information about the state, and the median voter strictly prefers not to acquire that information, then agents who are median voters in each state will never have their preferred alternative chosen.

\subsubsection{Preference Distributions}

The analysis above has looked at how decisions in the two states affect the willingness of the committee to learn the state. The primitives of the model, however, are not these decisions, but individual preferences. What kind of distributions of preferences across voters give rise to a collective preference for ignorance?

Recall that preferences of any agent $i$ are described by a pair $\left(x_{i}, y_{i}\right)$ of $i$ 's payoff from the reform in each state. The distribution of preferences of the group is then described by the distribution of voters over the $(x, y)$ space.

Figure 1 illustrates the space of individual payoffs. Letters $W, L, I_{Y}$, and $I_{X}$ indicate the sets of agents whose preference points lie in each of the four quadrants. Thus, $W$ represents the set of "sure winners", who receive a positive payoff from adopting the reform in either state. $L$ represents the set of "sure losers", who prefer the reform to be rejected in both states. We can refer to the sets $W$ and $L$ as the sets of committed voters, or partisans. $I_{X}$ and $I_{Y}$ are the sets of independent voters, whose preferred decision changes depending on the state. $I_{X}$ are independent voters that prefer the reform to be accepted when the state is $X$, but not when the state is $Y . I_{Y}$ are independent voters who receive a positive expected utility from the reform in state $Y$ but not in state $X$. 


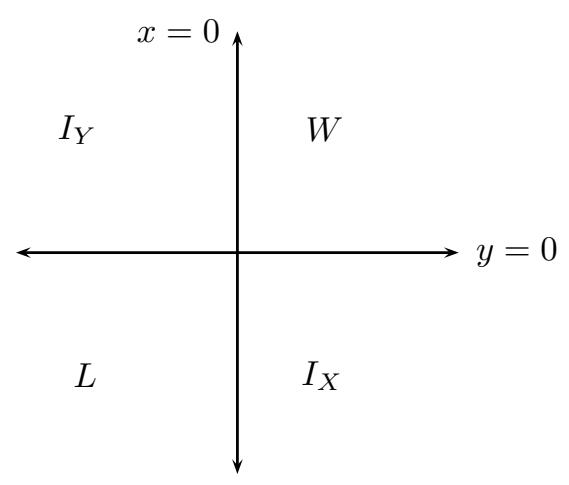

Figure 1: Distribution of preferences. The letters indicate the sets of voters whose payoffs lie in each of the four quadrants.

Suppose for simplicity that the mass of voters for whom $x_{i}=0$ or $y_{i}=0$ is zero, i.e. that (almost) nobody is indifferent when either state is revealed. For a given set of voters $S$, let $\# S$ denote the share of voters who belong to that set. Then the following result holds:

Proposition 2 The committee has a weak preference for ignorance if and only if

$$
\left|\# I_{X}-\# I_{Y}\right| \leq|\# W-\# L|
$$

\section{Proof. See Appendix}

This describes the necessary and sufficient condition for the committee to vote against acquiring information when doing so is costless or carries a price that is low relative to voters' payoffs. Information will thus be acquired if and only if the difference between the numbers of independents of the two types is larger than the difference between the number of sure winners and the number of sure losers. This prediction will be tested in the experimental part of the paper.

\subsection{Interpretation of Main Results}

The key message of the previous section is that the committee chooses not to acquire information when the numbers of independent voters are more similar than the numbers of partisans. This is likely when the reform entails uncertain outcomes, and the committee members do not share a common opinion on which outcome is better. 
Thus, decisions on divisive issues are likely to be made with less information. For example, suppose that a national legislature is considering a bill that would strengthen border controls. There is uncertainty over the effect this may have on the number of immigrants: on the one hand, the bill will make it harder for immigrants to enter illegally; on the other hand, immigrants who are already inside the country may be unwilling to leave, as they may be unable to return. If members of the legislature largely agree that immigration is desirable or that it is undesirable, they will seek to learn more about the likely outcome. If, however, immigration is a divisive issue - some members are in favor of immigration, some are against, and the two groups are relatively similar in size - then they are likely to vote on the bill in haste, without seeking information about its effects.

Another way to interpret Proposition 2 is to refer to the index of social fractionalisation $^{8}$, widely used in development literature. For a society divided into groups, the index of fractionalisation measures the probability that two randomly selected individuals belong to different groups. If there are only two groups, the index is higher when they are more similar in size. Proposition 2 then says that ignorance will be a collective decision if fractionalisation on the state-relevant dimension is larger than fractionalisation on the state-irrelevant dimension.

In fact, there is substantial research in development economics on the impact of social fractionalisation on economic growth, corruption, quality of governance, public good provision, and risk of civil war ${ }^{9}$. This paper suggests another mechanism through which fractionalisation can affect economic and social outcomes. Specifically, fractionalisation affects the degree to which the society chooses to be informed when making decisions. A society that is fractionalised in terms of its attitudes towards the likely outcomes of reforms will choose to vote on reforms in haste, without seeking expert advice or other sources of information.

Alternatively, consider a situation in which information about the state is dispersed among voters, with each voter receiving a signal about the state. If individual signals are very imprecise, then all voters have (almost) the same prior belief. By making these signals public, the society as a whole can become more informed about the state. Certain norms and institutions - such as freedom of speech, or a strong tradition of public debate can facilitate the exchange of individual signals. Proposition 2 suggests that societies that largely agree that some outcomes are better than others are more likely to support the existence of such institutions. On the other hand, societies that are more heterogeneous in terms of their preferences are, ceteris paribus, less likely to collectively support them.

Finally, it is useful to compare the collective preference for ignorance to the question of information aggregation through voting. Suppose again that information is dispersed among committee members. A number of papers (e.g. Feddersen and Pesendorfer, 1997)

\footnotetext{
${ }^{8}$ Described in e.g. Montalvo and Reynal-Querol (2005)

${ }^{9}$ See Mauro (1995), Easterly and Levine (1997), Collier (2001), Alesina et al. (2003), and others.
} 
have shown that voting aggregates information when all voters agree that the reform is better in one state than in the other. But if individual preferences are heterogeneous (in the sense of not being monotone in the state), information is not, in general, aggregated (Bhattacharya, 2013). This paper suggests that when individual preferences are sufficiently heterogeneous, the committee also chooses not to acquire information when it has an option to do so.

\subsection{Commitment to Learning}

This section will look at collective learning from a normative perspective. Specifically, it will examine when it is optimal for the committee to commit to learning the state prior to voting on the reform.

Commitment to learning is often found in various decision rules. For example, the legislative process often requires parliaments to have several readings before a law is passed. A formal constitutional guarantee of transparency or freedom of speech (or an informal tradition of public debate) can also serve as commitment devices imposing a certain amount of information acquisition. When are such commitments optimal?

Suppose that the committee can reject the reform without learning. A social planner is considering to impose a requirement that the committee must learn the state before voting on the reform. The planner does not know the state, but she knows individual preferences. Suppose that she judges outcomes based on a welfare function $w: \mathbb{R}^{I} \rightarrow \mathbb{R}$ which maps expected payoffs of individuals (given the information available to the planner) to social welfare. Normalize $w(0,0, .$.$) to zero - thus, a reform that produces a payoff vector z$ is welfare-improving if and only if $w(z)$ is positive. Let $\operatorname{sign}(\cdot)$ be the sign (positive or negative) of a scalar. To simplify notation, denote $d(z) \equiv g(z)-\frac{1}{2}$, so that given a vector of expected payoffs $z \in \mathbb{R}^{I}$, the reform is adopted if and only if $d(z)$ is positive.

Proposition 3 Commitment to learning is weakly optimal if sign $[d(\pi x+[1-\pi] y)] \neq$ $\operatorname{sign}[w(\pi x+[1-\pi] y)]$, and is weakly harmful if sign $[d(\pi x+[1-\pi] y)]=\operatorname{sign}[w(\pi x+[1-\pi] y)]$.

Proof. See Appendix.

Intuitively, this proposition says that commitment to learning is weakly preferable whenever the decision that the committee makes in ignorance is different from the welfaremaximizing decision.

How can we interpret this result? Suppose that the welfare function is utilitarian i.e. that $w(z)$ is an average of elements of $z$. Then a commitment to learning is optimal when the distribution of $\pi x_{i}+[1-\pi] y_{i}$ - that is, of ex ante expected payoffs - across voters has a mean and a median that are of different signs. Referring to Figure 1, this can happen when the distribution of payoffs is skewed along the "Southwest-Northeast" 
axis. This is the case when, for example, the majority of voters benefit from the reform in expectation, but there is a minority of individuals who each lose much if the reform is accepted (or vice versa). Hence, a constitutional guarantee of transparency can serve as a mechanism to protect a minority, and it is optimal when there is minority with a large stake in the reform.

\section{Experimental Design and Procedures}

In this section we experimentally test the main theoretical results described earlier - namely, the necessary and sufficient condition set out in Proposition 2. Specifically, we investigate whether a committee is substantially more likely to vote against acquiring information at little or not cost when the committee is more fractionalised on the state-relevant dimension that on the state-irrelevant dimension. To this end, we divided subjects into committees, and, as a main experimental treatment, varied the distribution of preferences of committee members.

The experiment consisted of several sessions, each of which included 24 subjects, split into two "pools" of equal size. Subjects faced decisions over 20 rounds. In each round, subjects inside each pool were randomly divided into three-member groups, representing committees. In every round, each group had to choose between two options, called Option $\mathrm{A}$ and Option B. ${ }^{10}$ At the beginning of each round, subjects were informed that the state of the world was either blue or red $^{11}$, with equal probability; the state was drawn independently across rounds. This probability distribution was chosen to reduce the cognitive burden and to prevent subjective overweighting of probabilities ${ }^{12}$. As in the model, the group first had to vote whether to learn the state. The state would be revealed if at least two out of three group members voted in favour of it. After that the group had to choose between Option A and Option B - again, the option supported by the majority was chosen. After the end of the round, subjects would be matched with other members of same pool, and a new round would begin. Since groups are redrawn every period, it is unlikely that subjects can play tit-for-tat or other history-contingent strategies $^{13}$.

Option A would, if selected, give each member of the group a payoff of 10 experimental tokens (ET), irrespective of the state. The payoff from Option B depended, as in the model, on the state of the world ${ }^{14}$. In each round, each subject was assigned a pair of

\footnotetext{
${ }^{10}$ These correspond to, respectively, status quo and reform in the model. We used more neutral labels in the experiment to avoid possible framing effects.

${ }^{11}$ These labels correspond to states $X$ and $Y$ in the model.

${ }^{12}$ As a robustness check, we also implemented (on a sample of 48 subjects) a treatment in which the state was blue with probability 0.75 . The effects of the treatment remained unchanged and are reported in Section 5.3.

${ }^{13}$ In Section 5 we indeed find no evidence that group or individual behaviour varies across time.

${ }^{14} \mathrm{~A}$ possible cause for concern is the fact that Option A, being the first of the two options, may serve
} 
integers from the set $\{1,2, \ldots, 19\}$; these numbers were her payoffs from Option B in the two states ${ }^{15}$. In the language of Proposition 2, each subject was in each round allocated to quadrant $W, L, I_{X}$ or $I_{Y}$ in the $(x, y)$ space. Then her payoff from each state was drawn randomly from a uniform distribution over the dashed lines from Figure 3 . The payoffs of every group member were known to all other members of the group.

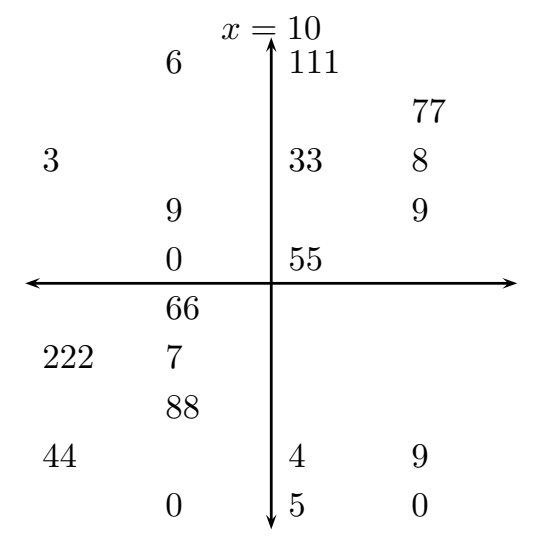

(a) State-relevant fractionalisation: Weak Preference for Ignorance

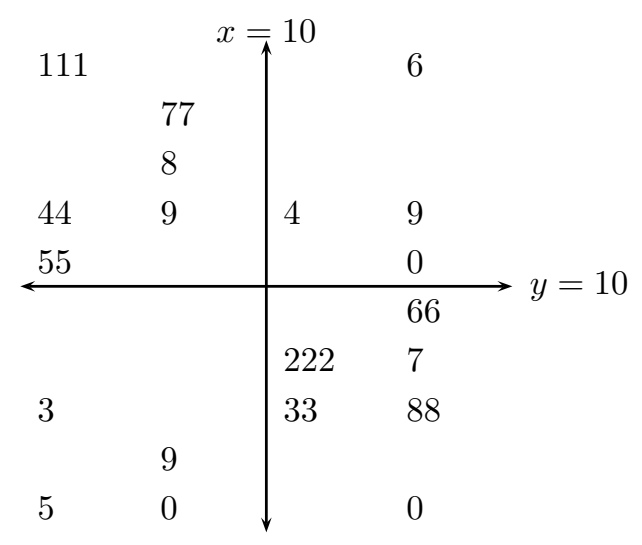

(b) State-irrelevant fractionalisation: No Weak Preference for Ignorance

Figure 2: Possible distributions of group members across the four quadrants. Each distribution is marked by a set of three identical digits. Each digit represents the location of one of the group members. Panel (a) represents distributions in which fractionalisation is larger on the state-relevant dimension, while panel (b) represents distributions in which fractionalisation is larger on the state-irrelevant dimension.

In total, there are twenty distinct ways of anonymously allocating 3 group members into four quadrants. They are presented in Figure 2. Under ten of these distributions, shown in panel (a), the condition $\left|\# I_{X}-\# I_{Y}\right| \leq|\# W-\# L|$ holds. In these instances, Proposition 2 predicts that the committee has a collective preference for ignorance and should vote against acquiring information. In the other ten distribution, shown in panel (b), the condition $\left|\# I_{X}-\# I_{Y}\right| \leq|\# W-\# L|$ fails to hold. In these situations, Proposition 2 predicts that the committee will vote in favour of acquiring information. The

as a focal point for subjects. Therefore, we control for order effects by flipping the labels in half of the sessions, calling the safe alternative "Option B", and the state-dependent alternative "Option A". As shown in Section 5 , the results are not affected by this.

${ }^{15}$ In terms of the model, these numbers corresponded to $x_{i}+10$ and $y_{i}+10$, where, as in the model, $x_{i}$ and $y_{i}$ represent the difference between agent $i$ 's payoff from the reform and her payoff from the status quo. 
difference between these two cases constitutes the main experimental treatment. We will refer to the the former case as ignorance treatment

During the twenty rounds, each individual was assigned to each for the twenty possible group configurations from Figure 2. Hence, each individual was subjected to ignorance treatment for ten out of twenty rounds in which she participated. Thus, we implement a within-subject design. However, to reduce the cognitive load on subjects, we kept each subject's state-dependent payoffs (and thus the quadrant to which she was allocated) unchanged for five rounds. Then, the subject was moved anticlockwise to an adjacent quadrant, and a new pair of state-dependent payoffs was randomly drawn. This procedure was repeated until every subject had visited every quadrant. Although individual valuations were kept constant for a span of 5 rounds, in every round each individual was allocated to a different group. Thus, from the perspective of each subject, payoffs of other group members changed after every round ${ }^{16}$.

The theoretical prediction in Proposition 2 refers to a weak preference for ignorance. Thus, it describes the decision of the committee when acquiring information is costless or involves a negligible cost. In the experiment we allow for either case to happen. Specifically, in each session, groups in each round can vote whether to acquire information at a cost $p$. We allow for three levels of $p$ : null cost $(p=0 \mathrm{ET})$, low cost $(p=0.1 \mathrm{ET})$, and high cost $(p=0.4 \mathrm{ET})$. The cost varies across sessions, but in each session, the same value of $p$ applies in every round. Note that all levels of the cost are small, in the sense that they are smaller than the possible difference in expected payoffs that may result from acquiring information. We also implement this information cost treatment because there is legitimate concern that individuals may be heterogeneous in their degree of ambiguity aversion (Machina and Siniscalchi, 2014). A way to control for this heterogeneity is to change the price individuals have to pay for acquiring information: ambiguity-averse individuals are more likely to keep voting to acquire information when the cost increases. The significance of our ignorance treatment after controlling for varying information costs can be seen as evidence in favour of our theoretical model even accounting for heterogeneity in the degree of ambiguity aversion.

To summarize, we follow a $2 \times 3$ design: one dimension represents the variation over whether or not ignorance treatment is applied, while the other represents three levels of information cost. As mentioned above, we also control for order effects between Option $\mathrm{A}$ and B. Individuals face a between-subjects information cost treatment and both fractionalisation configurations (following a within-subjects design in this last dimension). We conducted 6 sessions in total. Each session consisted of 22 independent rounds of information acquisition and option decisions; the first two rounds were practice rounds in which outcomes were not counted for final payoffs. Throughout the paper, we only use data generated from round three onward.

\footnotetext{
${ }^{16}$ See Appendix $\mathrm{C}$ for more details on how groups were formed.
} 
Table 1 summarizes the experimental design and the number of observations. In total, 144 subjects participated in the experiment across a span of 20 experimental rounds, which amounts to 960 groups observations and 2880 individual observations. Exactly half of the observations faced the ignorance treatment. In each round, subjects were informed they had 60 seconds to reach each a decision. The average time it took individuals to make each decision varied between 15.56 and 21.77 seconds, with an average of 18.6 seconds.

Further details about experimental procedures are available in Appendix B. Instructions and Experimental screens, translated into English, are shown in, respectively, Appendix E and Appendix F.

Table 1: Number of individual and group observations, based on 144 participating subjects, by treatments

\begin{tabular}{ccccc}
\hline & \multicolumn{4}{c}{ Information cost } \\
\hline Observations & Null cost & Low cost & High cost & Total \\
\hline Individual & 960 & 960 & 960 & 2,880 \\
Group & 320 & 320 & 320 & 960 \\
\hline
\end{tabular}

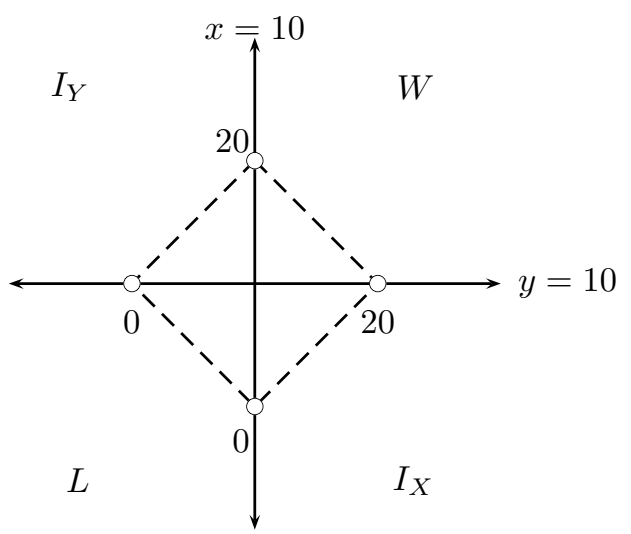

Figure 3: Possible experimental payoffs $\left(x_{i}, y_{i}\right)$ dependent on the State $X$ (Blue) or $Y$ (Red). Origin is $(10,10)$ ET 


\section{Experimental Findings}

\subsection{Main Results}

In this section we test the main theoretical result of the paper, summarised in Proposition 2, that groups in which fractionalisation is larger on the state-relevant dimension (that is, groups subjected to ignorance treatment) are less likely to vote to acquire information.

Figure 4 shows the frequency with which groups tend to acquire information under different values of information cost. Even when information is costless, groups do not always vote in favour of acquiring information. Overall, the fraction of instances in which information was acquired ranges from $67 \%$ when the cost of information was zero, to $28 \%$ when the cost of information was 0.4 ET. More importantly, across the three different levels of information cost, groups were substantially more likely to vote for ignorance when the theory predicts them to do so - under the ignorance treatment, groups have voted to to acquire information in $29 \%$ of of the time; compared to $60 \%$ of the time when not under ignorance treatment.

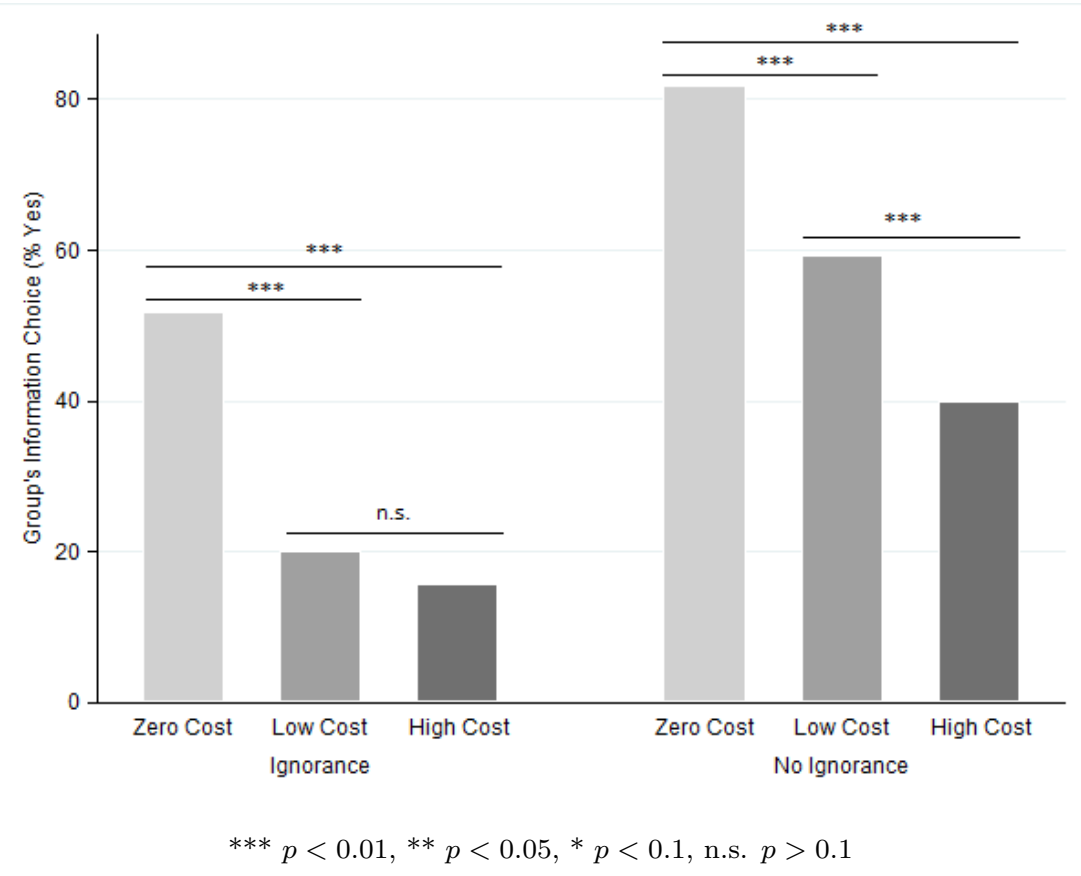

Figure 4: Group information acquisition with and without ignorance treatment.

We now look at the effect of the ignorance treatment on the group information acquisition decision. Specifically, we construct a dummy variable that equals one when the group has voted to acquire information. We regress it on a dummy variable that equals 
one when the condition $\left|\# I_{X}-\# I_{Y}\right| \leq|\# W-\# L|$ holds for the group - that is, when the group is subjected to the ignorance treatment - as well as on variables representing the cost of information in the particular session, and demographic controls.

Since groups are formed randomly in each round, group observations are independent variables. However, across the 20 rounds, groups are formed from the same pool of 12 subjects ${ }^{17}$. This can, in principle, cause standard errors to be correlated across rounds. To account for the possibility of such dependence, we cluster standard errors at the pool level $^{18}$. This is a conservative approach and should bias our results against finding statistical significance.

\section{- Table 3 here -}

Regression results are presented in Table 3. Column 1 shows that groups subjected to the ignorance treatment are 31.3 percentage points less likely to vote for acquiring information, compared to groups not facing ignorance treatment. The coefficient is large in magnitude and significant at the $1 \%$ level, suggesting a strong effect that is in line with the prediction of theoretical model.

Column 2 shows that increasing the cost of information to 0.1 and 0.4 ET reduces the frequency of information acquisition by, respectively, 27.2 and 39.1 percentage points, compared to the case when information is costless. However, if ignorance treatment is interacted with information cost dummies (column 3) the resulting coefficient is not statistically significant. This suggests that the cost of information does not affect the theoretical mechanism described in Proposition 2. There is also no evidence that group behaviour in early rounds is different from the behaviour in later rounds, which rules out possible learning channels at the group level. Columns 2 and 3 also control for order effect by including a dummy variable for sessions in which the safe alternative was labeled "Option B" - this does not seem to affect the main results.

Columns 4 and 5 show that the effect of the ignorance treatment is essentially unchanged after controlling for round fixed effects and for group-level control variables, including the percentage of female members, the percentage of students studying for economics or business degrees, the average risk-taking self-assessment levels, and the average participation in decision-making bodies ${ }^{19}$. Group-level controls also include a measure of payoff inequality within the group, defined as the Gini coefficient on the individual expected values of Option $\mathrm{B}^{20}$. We control for group inequality because there is concern

\footnotetext{
${ }^{17}$ See Appendix $\mathrm{C}$ for details on how groups were formed in each round.

${ }^{18}$ In our data, this procedure is equivalent to clustering on the "chunk" level done in Cooper and Kagel (2005).

${ }^{19}$ Although the associated coefficients are not reported here, they are available upon request.

${ }^{20}$ The significance and magnitude of our treatment effects do not change when the mean absolute deviation or the ratio between the maximum and minimum valuations of Option B are used instead of the Gini coefficient.
} 
that subjects may have other-regarding preferences (see Cooper and Kagel, 2016), which would induce them to select Option A, as that alternative gives the same payoff to all group members. This would discourage the groups from acquiring information. Nevertheless, the significance and magnitude of the ignorance treatment effect is robust to including inequality measures in the regressions ${ }^{21}$. Furthermore, once we control for these characteristics, the order effect.

To summarise, the experimental results provide evidence in favour of Proposition 2: groups that are more fractionalised on the state-relevant dimension than on the stateirrelevant dimension of preferences tend to acquire information substantially less often.

\subsection{Commitment to Learning and Welfare}

In this section, we provide evidence on the welfare effects associated with a commitment to learning the state. The theoretical prediction regarding such effects is described in Proposition Proposition 3.

We test this prediction by examining the contrapositive of Proposition 3. To do this, we construct an indicator variable that equals one whenever $\operatorname{sign}[d(\pi x+[1-\pi] y)]=$ $\operatorname{sign}[w(\pi x+[1-\pi] y)]$. Here, $d(\pi x+[1-\pi] y)$ represents the decision the group would have (theoretically) made without learning the state, while $w(\pi x+[1-\pi] y)$ represents the group's utilitarian welfare gain from choosing Option B instead of Option A. Thus, the indicator variable is equal to one whenever the mean and median expected gain from Option B (that is, the difference between the expected payoff from Option B and the payoff from Option A) across voters in the group are of the same sign.

We then regress this variable on two dummy variables, one of which indicates whether a commitment to learning is, on average, strictly optimal for the group, while the other indicates whether such a commitment is strictly harmful. These variables compare the aggregated payoffs the committee members would have received if the state were known to their payoffs observed from actual choices in the experiment. If Proposition 3 is correct, the coefficient should be negative for the first dummy, and positive for the second. As before, we cluster standard errors at the pool level.

\section{- Table 4 here -}

Table 4 summarises the results. It shows that the two coefficients have the expected signs, but only the first is significant at $10 \%$ level. However, when we perform a joint significance test on these two variables we reject, at a $10 \%$ significance level, the null hypothesis of no significance, even after adding various controls.

\footnotetext{
${ }^{21}$ While not affecting the treatment effect, the coefficients on group inequality measures are negative and significant at $5 \%$ level when controlling for round fixed effects. This provides some evidence in favour of the above intuition.
} 
We are cautious about interpreting this as strong evidence in favour of the theoretical predictions regarding welfare effects. The significance levels of the variables of interest, particularly of the strict welfare loss dummy, are mainly due to lack of sufficient variation in our experimental data. Among the 960 group observations, a strict welfare gain from commitment to learning was observed in only $9.4 \%$ of the cases, while a strict welfare loss was only observed in $2.7 \%$ of the cases.

\subsection{Robustness and External Validity}

\subsubsection{Individual behavior}

The theoretical logic of the model expects individuals to have fairly sophisticated reasoning. In the model, voter $i$ supports acquiring information if and only if $v_{i}$, the value of ignorance for $i$, is negative. This requires the voter to be able to predict the votes of other committee members when either state is revealed.

One may reasonably suspect that subject are not as forward-looking as the model expects them to be. It could be possible that they use simpler decision rules. For example, they may be only taking their own payoffs into consideration. In that case, they will be voting to acquire information when they belong to quadrants $I_{X}$ and $I_{Y}$, and voting against it when they belong to sets $W$ and $L$.

To address this concern, we perform individual-level regressions in which the dependent variable indicates whether the individual voted to acquire information. We regress this variable on a dummy that equals one whenever $v_{i}$ is negative - i.e. whenever the theoretical mechanism of the model predicts that an individual will vote to acquire information. We also control for the quadrant $-I_{X}, I_{Y}, W$ or $L$ - to which the individual belongs, for the cost of information, and individual characteristics. In all regressions, we compute robust standard errors clustered at the individual level to account for possible dependence between decisions across rounds.

The results are presented in Table 5. Column 1 shows that the theoretical mechanism is a strong predictor of the actual individual vote: an individual is 29.6 percentage points more likely to vote for acquiring information when the theory predicts her to do so. Column 2 suggests that, aside from the theoretical mechanism, individual payoffs (the quadrant to which she belongs) and the cost of information have an effect on individual decisions. Nevertheless, the coefficient on the theoretical mechanism is still highly significant, though smaller in magnitude. At the same time, Column 3 suggests that the information cost does not influence the degree to which that mechanism affects individual decisions, as the coefficients on the interaction terms are not significant.

Subsequent specifications show that the significance of the theoretical prediction is robust even after controlling for individual characteristics ${ }^{22}$ (column 4), round fixed ef-

\footnotetext{
${ }^{22}$ Among these individual variables, females and subjects who report higher willingness to undertake
} 
fects (column 5), and even for individual unobservable factors (column 6 which includes individual fixed effects, exploiting the within-subject design of the experiment).

Overall, we can conclude that an individual is significantly more likely to vote against acquiring information when the theory predicts him to do so.

- Table 5 here -

\subsubsection{Evidence of external validity}

In these section we again perform individual-level analysis. The aim is to examine factors that affect the probability that a subject has voted in accordance with theory.

To do this, we construct a dummy variable that is equal to one whenever the subject has voted in the way theory predicts her to vote. Specifically, the dummy equals one if the subject voted to acquire information and her $v_{i}$ was negative, or if she voted against acquiring information and her $v_{i}$ was positive; in all other cases, the dummy equals zero. We regress that variable on the information cost dummies, the quadrants to which the subject belonged, and individual demographic characteristics. The results are presented in Table 6.

An important result is the positive and significant coefficient on the number of associations in which a subject has participated. This suggests that individuals with more experience in actual collective decision-making bodies (for example, at secondary school, or university) are more likely to act in the way the model predicts them to. At the same time, subjects who assess themselves as more strategic in their behaviour are also more likely to vote according to theory. Additionally, the coefficient on the round (from 1 to 20) is also positive and significant, suggesting that learning is present: subjects become increasingly more likely to act in the way the model predicts them to.

All in all, these results suggests that the model is relatively better at predicting the behaviour of people who participate in collective decision-making, who have greater strategic competence, or who have simply been exposed to some learning in previous rounds of the experiment. In short, the model is most likely to make a correct prediction when subjects resemble the actual members of real-life committees the most. This provides evidence for the model's external validity.

$$
\text { - Table } 6 \text { here - }
$$

\subsubsection{Ambiguity aversion}

The model described in Section 2 assumes that individuals maximise expected utility. In reality, individuals may exhibit ambiguity aversion. Then they might be willing to

risks are significantly less likely to vote for information acquisition. High level of group inequality is also associated with a lower likelihood of an individual voting for acquiring information. 
acquire information even when the model predicts they should not. In that case, the experimental results would be biased in favour of acquiring information more often. Hence, allowing for ambiguity aversion means that our results are a lower bound on the collective preference for ignorance.

\subsubsection{Asymmetric prior beliefs}

The theoretical model holds for any prior belief about the state. To reduce cognitive burden on subjects, we performed the experiment in a setting when the prior was uniform. In this section, we test whether the theoretical channel proposed in Proposition 2 holds under asymmetric prior beliefs. For this purpose, we ran the experiment under a setup in which the probability that the state was "Blue" equaled 0.75. This experiment was performed on a sample of 48 subjects (equivalent to 16 groups in 20 rounds). They faced null information cost and high information cost treatments (in equal proportions); for all of them, the safe option was labeled "Option B" rather than "Option A".

Table 7 presents the regression results for a pooled sample of 96 subjects, of whom 48 faced the asymmetric prior treatment, and the other 48 faced a symmetric prior treatment under a similar setup with respect to cost and order effects. We can see that groups facing the asymmetric prior treatment $(\pi=0.75)$ exhibit lower rates of information acquisition. Nevertheless, they do not respond to the ignorance treatment differently than the groups facing the symmetric prior treatment. This is evidence in favor of Proposition 2 generalizability.

- Table 7

\section{Conclusions}

The aim of this paper was to analyze a committee's choice between acquiring information that reveals the state of the world and not learning it, prior to voting on a reform. Information was assumed to be costless. Because information can change the eventual collective decision, some committee members may be against acquiring information, and under some conditions, the share of these members may be enough for the committee to choose ignorance. It turned out that this choice depends on the group's decision in different states. Specific types of payoff distributions induce a collective preference for ignorance. The committee will choose to remain uninformed if and only if the group is more fractionalised on the state-relevant dimension than on the state-irrelevant dimension. Thus, groups that are sufficiently heterogeneous with respect to their attitude towards the reform will choose to vote on the reform without learning the state.

The experimental evidence supports the theoretical predictions on collective preference for ignorance and individual. We observe that groups are significantly more likely to vote 
for ignorance when the theory predicts them to do so. Controlling for possible learning and group composition do not change the result.

At the individual level, experimental data matches with theoretical results. Subjects with greater experience in decision-making bodies behave closer to theory, providing evidence for external validity.

\section{References}

Albrecht, James, Axel Anderson, and Susan Vroman, "Search by committee," Journal of Economic Theory, 2010, 145 (4), 1386-1407.

Alesina, Alberto, Arnaud Devleeschauwer, William Easterly, Sergio Kurlat, and Romain Wacziarg, "Fractionalization," Journal of Economic Growth, 2003, 8 (2), 155-194.

Anderson, Christopher J and Aida Paskeviciute, "How ethnic and linguistic heterogeneity influence the prospects for civil society: A comparative study of citizenship behavior," Journal of Politics, 2006, 68 (4), 783-802.

Austen-Smith, David and Jeffrey S Banks, "Information aggregation, rationality, and the Condorcet jury theorem," American Political Science Review, 1996, pp. 34-45.

Bhattacharya, Sourav, "Preference Monotonicity and Information Aggregation in Elections," Econometrica, 2013, 81 (3), 1229-1247.

Bouton, Laurent and Micael Castanheira, "One person, many votes: Divided majority and information aggregation," Econometrica, 2012, 80 (1), 43-87.

Cason, Timothy N. and Vai Lam Mui, "Uncertainty and resistance to reform in laboratory participation games," European Journal of Political Economy, 2005, 21 (3), 708-737.

Collier, Paul, "Implications of ethnic diversity," Economic policy, 2001, 16 (32), 127166.

Compte, Olivier and Philippe Jehiel, "Bargaining and majority rules: A collective search perspective," Journal of Political Economy, 2010, 118 (2), 189-221.

Cooper, David J and John H Kagel, "Are two heads better than one? Team versus individual play in signaling games," The American economic review, 2005, 95 (3), 477509 . 
_ and _, "Other-regarding preferences," The Handbook of Experimental Economics, Volume 2: The Handbook of Experimental Economics, 2016, p. 217.

Dewan, Torun and David P Myatt, "The qualities of leadership: Direction, communication, and obfuscation," American Political Science Review, 2008, 102 (03), 351-368.

Dewatripont, Mathias and Gerard Roland, "The design of reform packages under uncertainty," The American Economic Review, 1995, pp. 1207-1223.

Dohmen, Thomas, Armin Falk, David Huffman, and Uwe Sunde, "Individual risk attitudes: Measurement, determinants, and behavioral consequences," Journal of the European Economic Association, 2011, 9 (3), 522-550.

Easterly, William and Ross Levine, "Africa's growth tragedy: policies and ethnic divisions," The Quarterly Journal of Economics, 1997, pp. 1203-1250.

Feddersen, Timothy and Wolfgang Pesendorfer, "Voting behavior and information aggregation in elections with private information," Econometrica: Journal of the Econometric Society, 1997, pp. 1029-1058.

_ and _, "Convicting the innocent: The inferiority of unanimous jury verdicts under strategic voting," American Political Science Review, 1998, pp. 23-35.

Fernandez, Raquel and Dani Rodrik, "Resistance to reform: Status quo bias in the presence of individual-specific uncertainty," The American Economic Review, 1991, pp. 1146-1155.

Fischbacher, Urs, "z-Tree: Zurich toolbox for ready-made economic experiments," Experimental economics, 2007, 10 (2), 171-178.

Gerardi, Dino and Leeat Yariv, "Deliberative voting," Journal of Economic Theory, 2007, 134 (1), 317-338.

_ and _, "Information acquisition in committees," Games and Economic Behavior, 2008, 62 (2), 436-459.

Gersbach, Hans, "The value of public information in majority decisions," Economics Letters, 1991, 35 (3), 239-242.

_. "Public information and social choice," Social Choice and Welfare, 2000, 17 (1), 25-31.

- and Volker Hahn, "Information acquisition and transparency in committees," International Journal of Game Theory, 2012, 41 (2), 427-453. 
Gershkov, Alex and Balázs Szentes, "Optimal voting schemes with costly information acquisition," Journal of Economic Theory, 2009, 144 (1), 36-68.

Godefroy, Raphael and Eduardo Perez-Richet, "Choosing choices: Agenda selection with uncertain issues," Econometrica, 2013, 81 (1), 221-253.

Goeree, Jacob K. and Leeat Yariv, "An Experimental Study of Collective Deliberation," Econometrica, 2011, 79 (3), 893-921.

Goertz, Johanna MM and François Maniquet, "On the informational efficiency of simple scoring rules," Journal of Economic Theory, 2011, 146 (4), 1464-1480.

Guarnaschelli, Serena, Richard D. McKelvey, and Thomas R. Palfrey, "An Experimental Study of Jury Decision Rules," The American Political Science Review, 2000, $94(2), 407$.

Halevy, Yoram, "Ellsberg revisited: An experimental study," Econometrica, 2007, 75 (2), 503-536.

Hellwig, Christian and Laura Veldkamp, "Knowing what others know: Coordination motives in information acquisition," The Review of Economic Studies, 2009, 76 (1), $223-251$.

Hirshleifer, Jack, "The private and social value of information and the reward to inventive activity," The American Economic Review, 1971, pp. 561-574.

Klibanoff, Peter, Massimo Marinacci, and Sujoy Mukerji, "A smooth model of decision making under ambiguity," Econometrica, 2005, 73 (6), 1849-1892.

Lizzeri, Alessandro and Leeat Yariv, "Sequential Deliberation," 2013, Mimeo.

Machina, Mark J and Marciano Siniscalchi, "Ambiguity and ambiguity aversion," Handbook of the Economics of Risk and Uncertainty, 2014, 1, 729-807.

Mannix, Elizabeth and Margaret A Neale, "What differences make a difference? The promise and reality of diverse teams in organizations," Psychological science in the public interest, 2005, 6 (2), 31-55.

Mauro, Paolo, "Corruption and growth," The quarterly journal of economics, 1995, pp. 681-712.

Messner, Matthias and Mattias K Polborn, "The option to wait in collective decisions and optimal majority rules," Journal of Public Economics, 2012, 96 (5), 524-540. 
Moldovanu, Benny and Xianwen Shi, "Specialization and partisanship in committee search," Theoretical Economics, 2013, 8 (3), 751-774.

Montalvo, José G and Marta Reynal-Querol, "Ethnic polarization, potential conflict, and civil wars," American economic review, 2005, pp. 796-816.

Myatt, David P and Chris Wallace, "Endogenous information acquisition in coordination games," The Review of Economic Studies, 2012, 79 (1), 340-374.

Oliveros, Santiago, "Abstention, ideology and information acquisition," Journal of Economic Theory, 2013, 148 (3), 871-902.

Palfrey, Thomas R., Experiments in Political Economy, Vol. 22013.

Persico, Nicola, "Committee design with endogenous information," The Review of Economic Studies, 2004, 71 (1), 165-191.

Plott, Charles R. and Morgan Llewellyn, "Information transfer and aggregation in an uninformed committee: A model for the selection and use of biased expert advice," European Journal of Political Economy, 2015, 40, 208-223.

Segal, Uzi, "The Ellsberg paradox and risk aversion: An anticipated utility approach," International Economic Review, 1987, pp. 175-202.

Strulovici, Bruno, "Learning while voting: Determinants of collective experimentation," Econometrica, 2010, 78 (3), 933-971.

Visser, Bauke and Otto H Swank, "On committees of experts," The Quarterly Journal of Economics, 2007, 122 (1), 337-372. 


\section{Appendix}

\section{A. Proofs}

\section{Proof of Proposition 1}

The value of ignorance for agent $i$ is

$$
v_{i}=\left(\pi x_{i}+[1-\pi] y_{i}\right) g(\pi x+[1-\pi] y)-\pi x_{i} g(x)-(1-\pi) y_{i} g(y)
$$

1. If $g(x)=g(y)=g(\pi x+[1-\pi] y)$, then $v_{i}=0, \forall i \in I$, so all agents are indifferent between learning and not learning.

2. If $g(x)=g(y)=0$ and $g(\pi x+[1-\pi] y)=1$, then $v=\pi x+[1-\pi] y$, so $g(v)=$ $g(\pi x+[1-\pi] y)=1$

3. If $g(x)=g(y)=1$ and $g(\pi x+[1-\pi] y)=0$, then $v=-(\pi x+[1-\pi] y)$, so $g(v)=1-g(\pi x+[1-\pi] y)=1$.

4. If $g(x)=1$ and $g(y)=g(\pi x+[1-\pi] y)=0$, then $v=-\pi x$, so $g(v)=1-g(\pi x)=$ $1-g(x)=0$.

5. In a similar way, it can be shown that $g(y)=1$ and $g(x)=g(\pi x+[1-\pi] y)=0$ imply $g(v)=0$.

6. If $g(x)=0$ and $g(y)=g(\pi x+[1-\pi] y)=1$, then $v=\pi x$, so $g(v)=g(\pi x)=$ $g(x)=0$.

7. In a similar way, it can be shown that $g(y)=0$ and $g(x)=g(\pi x+[1-\pi] y)=1$ imply $g(v)=0$.

\section{Proof of Proposition 2}

Recall the the committee has a collective preference for ignorance whenever $g(x)=$ $g(y)=0$ or $g(x)=g(y)=1$. The former condition says that

$$
\# L+\# I_{X} \geq \frac{1}{2} \text { and } \# L+\# I_{Y} \geq \frac{1}{2}
$$

while the latter says that

$$
\# W+\# I_{X} \geq \frac{1}{2} \text { and } \# W+\# I_{Y} \geq \frac{1}{2}
$$


Inequality (1) is equivalent to the condition $\# L+\min \left\{\# I_{X}, \# I_{Y}\right\} \geq \frac{1}{2}$, while (2) is equivalent to the condition $\# W+\min \left\{\# I_{X}, \# I_{Y}\right\} \geq \frac{1}{2}$. The committee has a collective preference for ignorance if and only if at least one of these conditions holds. Hence, the committee has a collective preference for ignorance if and only if

$$
\max \{\# W, \# L\}+\min \left\{\# I_{X}, \# I_{Y}\right\} \geq \frac{1}{2}
$$

which is equivalent to $\max \{\# W, \# L\}+\min \left\{\# I_{X}, \# I_{Y}\right\} \geq \min \{\# W, \# L\}+\max \left\{\# I_{X}, \# I_{Y}\right\}$. Rearranging, we obtain $\max \left\{\# I_{X}, \# I_{Y}\right\}-\min \left\{\# I_{X}, \# I_{Y}\right\} \leq \max \{\# W, \# L\}-\min \{\# W, \# L\}$. This is equivalent to $\left|\# I_{X}-\# I_{Y}\right| \leq|\# W-\# L|$.

\section{Proof of Proposition 3}

If $g(x)=g(y)=g(\pi x+[1-\pi] y)$, then the decision on the reform is the same with or without information, so a commitment to learning has no effect. If $g(x) \neq g(y)$, the committee chooses to learn the state, so a commitment to learning again has no effect. The only case when it does have an effect is when $g(x)=g(y) \neq g(\pi x+[1-\pi] y)$. Suppose that $g(x)=g(y)=1$ and $g(\pi x+[1-\pi] y)=0$. Then, $d(\pi x+[1-\pi] y)<$ 0 . Without a commitment to learning, the committee votes not to acquire information and then rejects the reform, giving each member a payoff of zero. With a commitment to learning, the reform is adopted in either state, so the expected payoff of each voter $i$ is $\pi x_{i}+[1-\pi] y_{i}$. Commitment to learning is then socially optimal iff $w(\pi x+[1-\pi] y)>0$. Now suppose that $g(x)=g(y)=0$ and $g(\pi x+[1-\pi] y)=1$, hence $d(\pi x+[1-\pi] y)>0$. Without a commitment to learning, the committee votes not to learn the state and then adopts the reform, giving each voter $i$ an expected payoff of $\pi x_{i}+[1-\pi] y_{i}$. With a commitment to learning, the reform is rejected in either state, and the payoff of each voter is 0. Commitment to learning is then socially optimal iff $0>w(\pi x+[1-\pi] y)$. Hence, whenever $\operatorname{sign}[d(\pi x+[1-\pi] y)] \neq$ $\operatorname{sign}[w(\pi x+[1-\pi] y)]$, commitment to learning either has no effect, or is socially preferable. But when sign $[d(\pi x+[1-\pi] y)]=\operatorname{sign}[w(\pi x+[1-\pi] y)]$, commitment to learning either has no effect, or is socially harmful.

\section{B. Experimental Procedures and Sample Character- istics}

Experimental sessions were run at the Group and Laboratory for Experimental Economics (GLEE) at Universidad del Rosario between May and September 2016. The subjects were undergraduate students recruited from a GLEE pool across all disciplines. Each 
subject participated in only one experimental session. Characteristics of the experimental sample are described in Appendix B.

Immediately after entering the laboratory, the subjects read the instructions. After 10 minutes, an experimental administrator read them aloud. The instructions contained several frequently asked questions with their corresponding answers to ensure better understanding of the experiment. The span of time during which each subject made choices relevant for the experiment was less than 20 minutes (the total length of each experimental session was approximately 80 minutes). The experiment was computerized using z-Tree experimental software (Fischbacher, 2007). Sample instructions, translated into English, are presented in Appendix E.

In the beginning of each round, each subject was presented with a screen showing her payoffs and those of other members of the group from Option A, and from Option B in each of the states. The subject was then asked to vote for or against acquiring information at the cost used in that session. If the committee had chosen not to acquire information, subjects saw the same table of relevant payoffs and a reminder of the committee's information acquisition decision. If the committee had decided to acquire information, the state was revealed and subjects were shown a table of payoffs under each option, minus the cost of information. They were then asked to select the option they preferred. At the end of the round, the computer revealed to each subject individual information acquisition decisions and option choices, as well as group decisions, the payoff relevant state and individual payoffs. Once every subject had confirmed the results, the next round started with the computer randomly forming new groups. This process was repeated for twenty rounds. At the end of the session, subjects were asked several sociodemographic and behavioral questions.

Earnings were calculated in terms of ET and exchanged into Colombian pesos at the rate of $1 \mathrm{ET}$ to $\mathrm{COP} 75$, which is equivalent to $40 \mathrm{ET}$ to $\$ 1$. The total payment to each subject equaled the sum of her earnings over the twenty rounds (not including the first two practice rounds), plus a show-up fee that was equivalent to $\$ 3.5$. The average payment was approximately $\$ 10$. Payments were privately distributed at the end of the session.

Table 2 shows the characteristics of out subject pool. $54 \%$ of our subjects are females, and $60 \%$ are undergraduates from departments other than business or economics departments. $93 \%$ of subjects have had some sort of experience voting in school or college elections, and $70 \%$ - in local or national elections. Nearly $63 \%$ have actively participated in decision-making bodies (either in the school, college or other).

We also collected data on subjects' willingness to undertake risks. Following Dohmen et al. (2011), we asked subjects how willing they are to take risks on a 0 to 10 scale, where 0 represents "not at all willing to take risks" and the value 10 meaning "very willing to take risks". We find that the subjects have a moderate risk aversion attitude (mean 6.5). Finally, we asked our subjects to describe the strategy they implemented when deciding 
Table 2: Sample descriptive statistics

\begin{tabular}{|c|c|c|c|c|c|c|c|c|c|c|}
\hline & \multirow{3}{*}{$\begin{array}{c}(1) \\
\text { Mean }\end{array}$} & \multirow{3}{*}{$\begin{array}{c}(2) \\
\text { Min }\end{array}$} & \multirow{3}{*}{$\begin{array}{c}(3) \\
\operatorname{Max}\end{array}$} & \multirow{3}{*}{$\begin{array}{l}(4) \\
\text { Sd }\end{array}$} & $(5)$ & (6) & (7) & (8) & (9) & $(10)$ \\
\hline & & & & & \multicolumn{3}{|c|}{ Mean by Info Cost } & \multicolumn{3}{|c|}{ pval from $H_{0}$ : } \\
\hline & & & & & Zero & Low & High & $(5)=(6)$ & $(6)=(7)$ & $(5)=(7)$ \\
\hline Female & 0.54 & 0.00 & 1.00 & 0.50 & 0.48 & 0.54 & 0.60 & 0.545 & 0.541 & 0.223 \\
\hline Age & 20.56 & 14.00 & 36.00 & 3.12 & 20.85 & 19.94 & 20.88 & 0.178 & 0.099 & 0.975 \\
\hline Socieconomic strata & 3.63 & 2.00 & 6.00 & 0.97 & 3.63 & 3.77 & 3.48 & 0.440 & 0.131 & 0.501 \\
\hline Weekly expenses (USD) & 42.9 & 3.4 & 622.5 & 71.7 & 40.9 & 55.0 & 32.7 & 0.413 & 0.197 & 0.263 \\
\hline Academic semester & 5.39 & 1.00 & 10.00 & 2.98 & 5.31 & 4.96 & 5.90 & 0.569 & 0.132 & 0.320 \\
\hline Econ/Business undergrad & 0.40 & 0.00 & 1.00 & 0.49 & 0.38 & 0.48 & 0.35 & 0.307 & 0.218 & 0.834 \\
\hline Risk taking level & 6.53 & 0.00 & 10.00 & 1.75 & 6.79 & 6.42 & 6.40 & 0.283 & 0.955 & 0.270 \\
\hline Info Strategy & 2.26 & 1.00 & 3.00 & 0.71 & 2.23 & 2.33 & 2.23 & 0.473 & 0.453 & 1.00 \\
\hline Option Strategy & 2.01 & 1.00 & 3.00 & 0.77 & 2.44 & 1.77 & 1.81 & 0.000 & 0.795 & 0.000 \\
\hline \multicolumn{11}{|l|}{ Voting experience: } \\
\hline High School vote & 0.91 & 0.00 & 1.00 & 0.29 & 0.90 & 0.92 & 0.92 & 0.730 & 1.00 & 0.730 \\
\hline College vote & 0.67 & 0.00 & 1.00 & 0.47 & 0.69 & 0.56 & 0.75 & 0.210 & 0.054 & 0.501 \\
\hline Voted in school or college & 0.93 & 0.00 & 1.00 & 0.26 & 0.92 & 0.92 & 0.96 & 1.00 & 0.404 & 0.404 \\
\hline Regional vote & 0.67 & 0.00 & 1.00 & 0.47 & 0.65 & 0.60 & 0.77 & 0.677 & 0.080 & 0.182 \\
\hline Congress vote & 0.35 & 0.00 & 1.00 & 0.48 & 0.25 & 0.31 & 0.48 & 0.501 & 0.097 & 0.020 \\
\hline President vote & 0.53 & 0.00 & 1.00 & 0.50 & 0.50 & 0.48 & 0.60 & 0.840 & 0.223 & 0.310 \\
\hline Voted in at least once & 0.70 & 0.00 & 1.00 & 0.46 & 0.69 & 0.63 & 0.79 & 0.524 & 0.074 & 0.250 \\
\hline \multicolumn{11}{|c|}{ Decision Making (DM) Body experience: } \\
\hline High School Board & 0.54 & 0.00 & 1.00 & 0.50 & 0.63 & 0.52 & 0.48 & 0.307 & 0.687 & 0.154 \\
\hline College Board & 0.13 & 0.00 & 1.00 & 0.33 & 0.15 & 0.10 & 0.13 & 0.542 & 0.752 & 0.768 \\
\hline Other Board & 0.04 & 0.00 & 1.00 & 0.20 & 0.02 & 0.04 & 0.06 & 0.562 & 0.650 & 0.312 \\
\hline At least one & 0.63 & 0.00 & 1.00 & 0.49 & 0.73 & 0.58 & 0.56 & 0.135 & 0.839 & 0.090 \\
\hline
\end{tabular}

Note: Socioeconomic strata is 1 for poorest and 6 for richest households; Academic semester goes from 1 to 10; Econ/Business related undergrads (includes Economics, International Business Administration and Finance and International Trade students); Risk taking level takes values from 0 to 9 , where 0 represents "not at all willing to take risks" and 9 means "very willing to take risks"); Info and Option strategy is related to how strategic individuals were when deciding on information acquisition or on options A and B (categories for students' responses, being 1 the less strategic behavior -p.eg concerned only on his own payoffs- and 3 the most -p.eg concerned on others' payoffs and their potential choices-); Voting experience: Whether an individual has voted in school, college, local, congress or presidential elections; Decision Making Body (DM) experience: Whether an individual has participated actively in high school decision boards, college boards or other. 
whether to acquire information and which option to choose. We categorize their responses depending on increasing levels of strategic behavior, with 1 representing the least strategic behavior (e.g. based on one's own payoff only) and 3 being the most strategic (e.g. based on others' payoffs and their potential choices). Individuals, on average, report being quite strategic when making information acquisition decisions (the mean is 2.26). It can be seen that the our sample is balanced across information price treatments (see columns $8-9)$.

\section{Group Formation in Experiment}
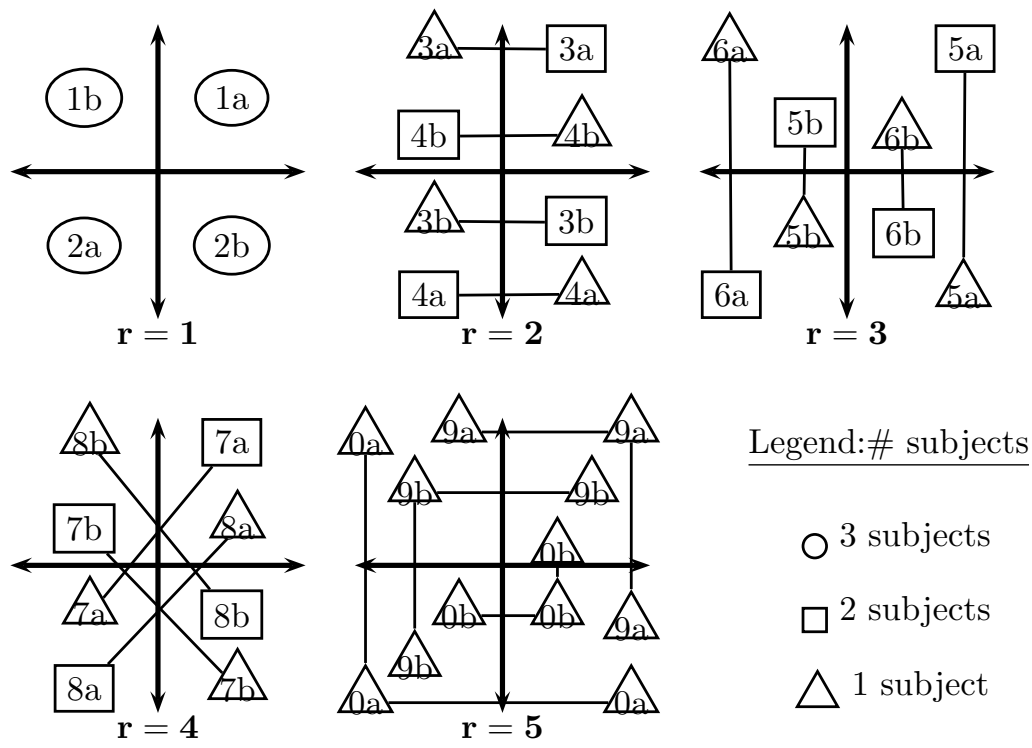

Figure 5: fractionalisation Treatments by rounds

Figure 5 summarises group layouts that individuals face over 5 consecutive rounds $(r=$ $1, \ldots, 5)$ if they belong to a given quadrant. Each oval, square, and triangle represents a set of, respectively, three, two, and one subject. Shapes connected with a line represent a single three-member experimental group. Groups are labeled with a number and a letter; these labels match those used in Figure 2. For instance, suppose that a subject is allocated to quadrant $W$ in the first round and randomly given state-dependent payoffs from the set depicted in Figure 3. Then in the first round she will belong to group $1 a$ (and thus will not face ignorance treatment). In the next round, she will keep her state-dependent payoffs, and can be randomly allocated to the groups $3 a$ or $4 b$. Her state-dependent payoffs will remain unchanged over five consecutive rounds. In round 6 she will be allocated to the quadrant $I_{Y}$, a new pair of state-dependent payoffs (which she will again retain over five 
consecutive rounds) will be randomly drawn for her, and she will be put in group $1 b$. Over the course of the session, each subject will spend five rounds in each of the four quadrants.

From Figure 5 one can see that over the course of a session, each subject will face each of the 20 possible group configurations shown in Figure 2. Note that a half of all subjects face the ignorance treatment and the other half do not. This design also allows to control for order effects or anchoring effects, given that there will always be the same proportion of subjects starting in different quadrants. Note also that the groups depicted in Figure 5 are formed from a pool of 12 subjects. In each session, we had 24 subjects, split into two pools.

\section{Regression Tables}




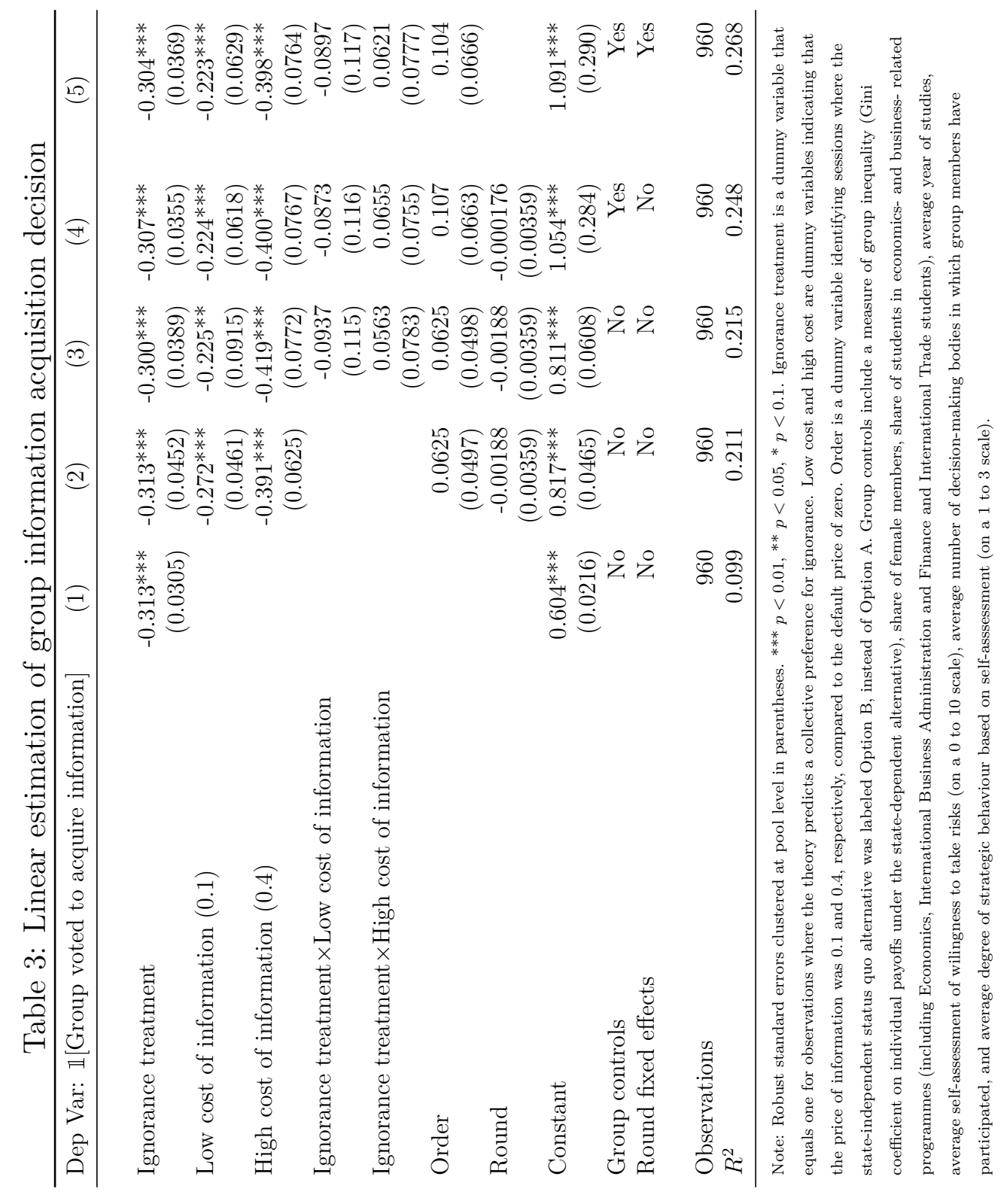




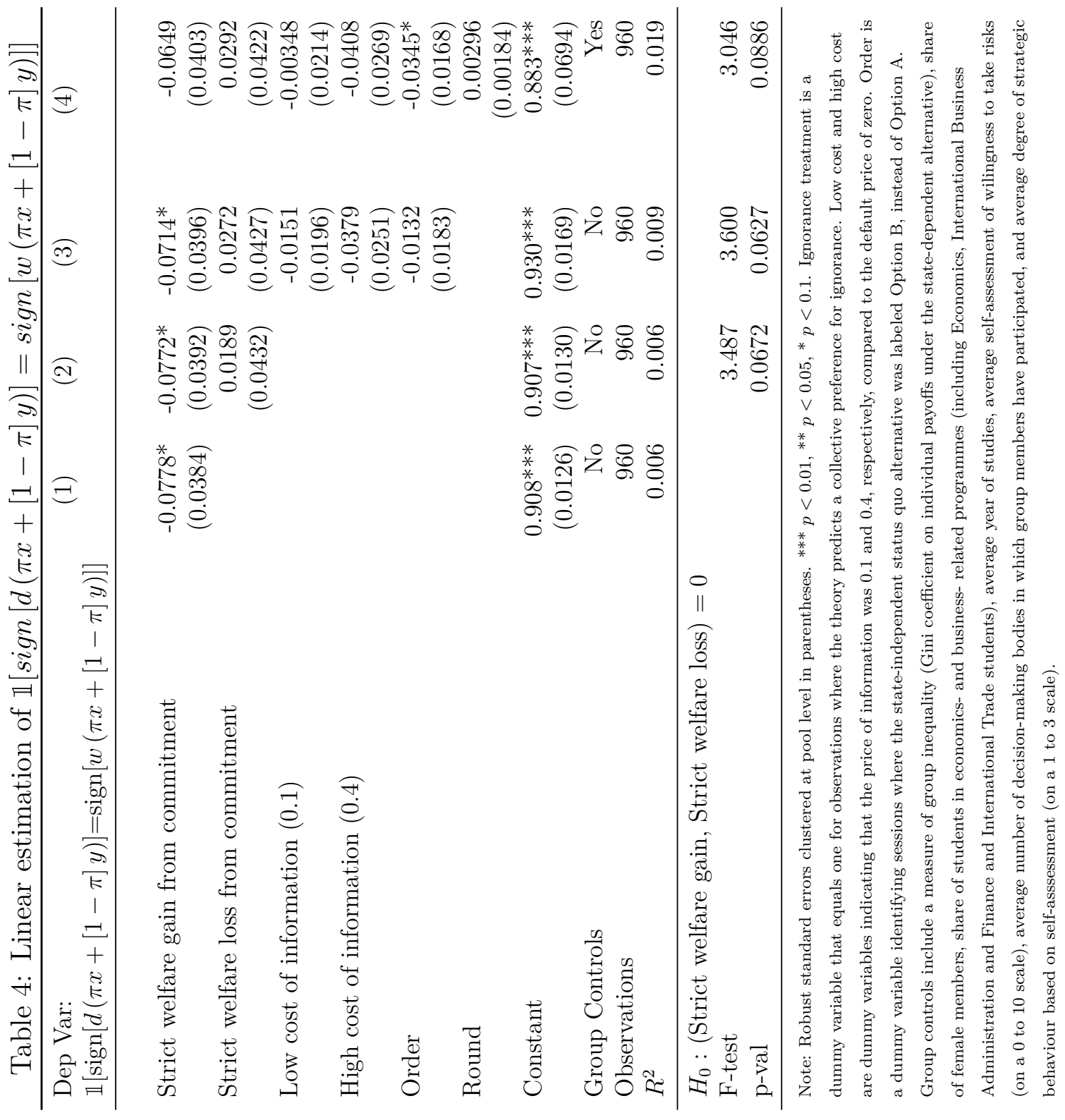




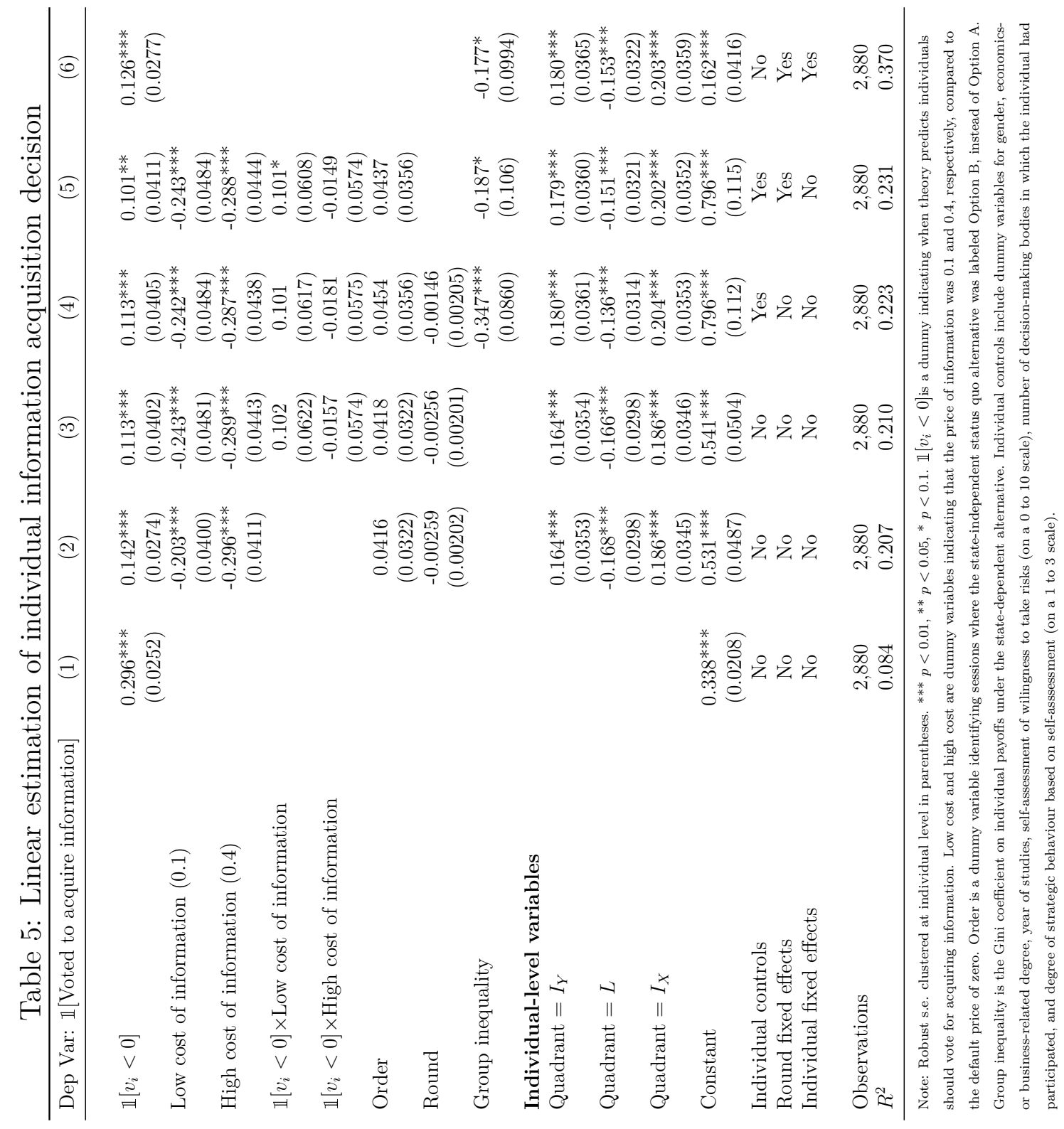


Table 6: Linear estimation of the consistency of individual votes with theoretical prediction

Dep Var: $\mathbb{1}$ [Vote consistent with theory]

(1)

(2)

(3)

$(4)$

Low cost of information (0.1)

$\begin{array}{lll}0.0948^{* * *} & 0.0948^{* * *} & 0.0992^{* * *} \\ (0.0303) & (0.0304) & (0.0288) \\ 0.0521^{*} & 0.0521^{*} & 0.0698^{* *} \\ (0.0276) & (0.0276) & (0.0268)\end{array}$

Order

$\begin{array}{lll}-0.00764 & -0.00764 & 0.00730\end{array}$

Quadrant $=I_{Y}$

(0.0238)

$(0.0239) \quad(0.0258)$

$\begin{array}{lll}0.0208 & 0.0276 & 0.0276\end{array}$

$\begin{array}{lll}(0.0361) & (0.0362) \quad(0.0371)\end{array}$

Quadrant $=L$

Quadrant $=I_{X}$

Group inequality

$0.154^{* * *} \quad 0.167^{* * *} \quad 0.167^{* * *}$

$\begin{array}{lll}(0.0290) & (0.0295) \quad(0.0300)\end{array}$

$\begin{array}{lll}0.0347 & 0.0422 & 0.0422\end{array}$

$(0.0356) \quad(0.0353) \quad(0.0363)$

$-0.150^{*} \quad-0.150^{*}$

Female

(0.0794)

$-0.0783^{* * *}$

(0.0814)

Econ/Business programmes

$(0.0227)$

0.0429

(0.0267)

$-0.00137$

$(0.00750)$

0.00417

(0.00634)

Number of of decision-making bodies

$0.0421^{* *}$

(0.0190)

Strategy

$0.0304^{* *}$

$(0.0147)$

Round

$0.00460^{* *}$

$0.00460^{* * *}$

$0.00508^{* * *}$

$0.00508^{* * *}$

Constant

(0.00189)

(0.00176)

$(0.00180)$

(0.00184)

$0.548^{* * *}$

$0.496^{* * *}$

$0.413^{* * *}$

$0.627^{* * *}$

Individual fixed effects

(0.0334)

No

Obs

2,880

(0.0410)

(0.0843)

(0.0377)

$R^{2}$

0.010

2,880

No

Yes

2,880

2,880

0.026

0.042

0.116

Robust s.e. clustered at individual level in parentheses. $* * * p<0.01,{ }^{* *} p<0.05,{ }^{*} p<0.1$. Low cost and high cost are dummy variables indicating that the price of information was 0.1 and 0.4 , respectively, compared to the default price of zero. Order is a dummy variable identifying sessions where the state-independent status quo alternative was labeled Option B, instead of Option A. Group inequality is the Gini coefficient on individual payoffs under the state-dependent alternative. Individual controls include dummy variables for gender, economics- or business-related degree, year of studies, self-assessment of wilingness to take risks (on a 0 to 10 scale), number of decision-making bodies in which the individual had participated, and degree of strategic behaviour based on self-asssessment (on a 1 to 3 scale). 


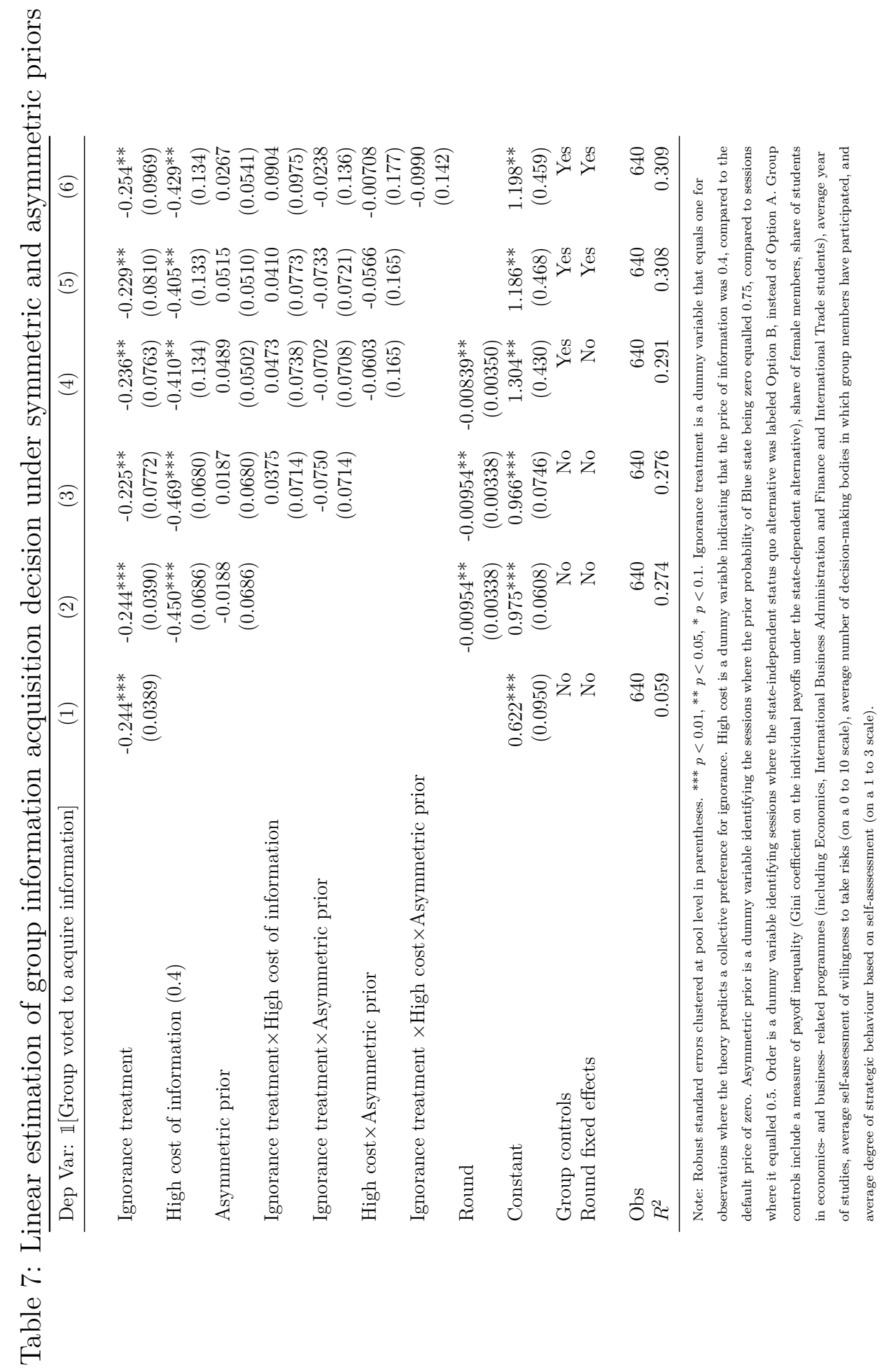




\section{E. Instructions}

\section{General Instructions}

Welcome. We thank you for participating in this experiment of group decisions.

From now on it is forbidden to communicate with the other participants in this room. Please remain silent and turn off your cellphone. The use of cellphones and calculators is strictly prohibited.

If you have questions on the experiment raise your hand and one of us will come to your desk to answer it. Do not ask any questions aloud.

All the information you provide to us during this experiment will be used for strictly academic purposes and will not be disclosed to anyone. Both your decisions and your payoffs will be confidential. No one will know the actions you took, or how much money you will receive at the end of the session.

For participating until the end of this experiment you will receive 10,000 pesos. In addition, depending on your actions and the actions of other participants, you can earn more money. During this activity we will talk in terms of Experimental Currency Units (ECU) instead of Colombian Pesos. Your payments will be computed in terms of ECU and will then be exchanged to Colombian pesos at the end of the experiment, according to this exchange rate:

$1 \mathrm{ECU}=75$ Pesos

If you do not wish to participate in the experiment, you may now leave the room. If you wish to participate, please read and sign the sheet that reads Informed Consent. 


\section{Experiment Instructions}

This is an experiment on group decisions in which you must participate throughout 22 rounds ( 2 practice rounds and 20 rounds that count for your payments). In each round you will be randomly assigned to a group of three (3) participants in this room. Group members are anonymous and will be reassigned to a new group at the end of each round of the experiment.

In each round you must make two decisions that are detailed below. Your payments in this experiment will be defined at the end of the activity based on the aggregated earnings of all rounds. Before we begin, we will have two practice rounds that will not affect your potential payoff.

\section{General Setting}

In each round, all members of a group must choose between two Options: Option A and Option B. The choice of the group regarding the Options will be defined by the simple majority rule: as groups are made up of three people, if at least two of them choose Option A and the remaining participant chooses Option B, Option A will determine the payments for ALL members of the group. However, if at least two of them choose Option B and the remaining participant chooses Option A, Option B will determine the payments for ALL members of the group.

Your payments in each round, and those of the other members of your group, will depend on the computer choosing one of two Possible Scenarios: Blue or Red. In each round the computer will randomly select one of these Scenarios (Blue or Red) with equal probability, that is, equal to $50 \%$, which is equivalent to tossing a coin. The Relevant Scenario for payment will be the same for all the members of your group.

You will know, in each round, how much you can earn if the group chooses Option A or Option B under any of the two Possible Scenarios (Blue or Red). You will also know how much would the other two members of your group earn in each of this 
cases. NOBODY in this room knows if the Relevant Scenario for payment is the Blue or the Red Scenario.

However, in each round, and before the group decides over the Options A or B, each member can choose if she wants the group to Acquire Information on which is the Relevant Scenario for payment in that round at a price of 0.4 ECU. The choice of the group regarding Information Acquisition will be defined by the simple majority rule. Hence, if at least two members want the group to acquire information to learn which is the Relevant Scenario, all members of that group must pay a price of $0.4 \mathrm{ECU}$, and the Relevant Scenario for payments will be known before deciding over Options A or B. But, if at least two of them DO NOT want the group to acquire information to learn which is the Relevant Scenario, the Relevant Scenario will not be known before deciding over Options A or B.

Next we summarize the decisions you must make.

\section{Decisions}

\section{Information Acquisition:}

Your first decision is whether you want the group to acquire information to learn the Relevant Scenario (Blue or Red) in this round, or not. The individual price for learning the Scenario is 0.4 ECU. We expect you to make your decision in less than 60 seconds; a timer on the screen will indicate the time that is running in each round (see Screen 1 in Appendix).

If at least two group participants decide to Acquire Information so as to know which is the Relevant Scenario, all group members must pay 0.4 ECU and will learn if the Relevant Scenario is Blue or Red. Otherwise, when most of the group decides not to Acquire Information, there will be no charge and no one will have information on the Relevant Scenario. All members of the group will be informed of the group's decision and the payments each would receive after selecting Options A or B described above. 


\section{Choice of Alternatives:}

In accordance with the above decision, each participant must decide next if she wishes the group to select Option A or Option B:

- Option A: If the group chooses this option, your payoffs will be of $10 \mathrm{ECU}$ regardless of the Relevant Scenario. That is, whether the Relevant Scenario is Blue or Red, if most members of the group select Option A, each individual's payment, without discounting the Information Acquisition decision, will be of $10 \mathrm{ECU}$.

- Option B: If the group chooses this option, your payments will depend on the Relevant Scenario randomly selected by the computer. This payoff, without discounting the Information Acquisition decision, could be between 1 ECU and $19 \mathrm{ECU}$.

We expect you to make your decision in less than 50 seconds; a timer on the screen will indicate the time that is running in each round (see Screens 2 and 3 for the cases when information was acquired and when it was not).

\section{Additional details}

Recall that both you and the other two participants of your group have the same information regarding the probability of occurrence of each Possible Scenario (Blue and Red Scenarios are equally likely to occur in each round), and on the payments each participant will receive under both Options (A and B), given both Possible Scenarios (Blue and Red). During the rounds that count for final earnings, payments each individual in the room will receive will be the same for five (5) consecutive rounds, but the payments you observe from your colleagues may change, considering that group composition varies in each round. At the end of each round you will receive feedback on your group's decisions and the earnings for each member (see Screen 4) 


\section{Payments from the Activity}

In addition to the 10,000 pesos for participating in this activity, at the end of the 22 rounds, the computer will add ALL your earnings from each round to determine your payment; this will be computed depending on the Option (A or B) chosen by the group for each round. If during a particular round the group decided to acquire information on the Relevant Scenario, the price for this information will be deducted from your earnings. 


\section{F. Experimental screens}

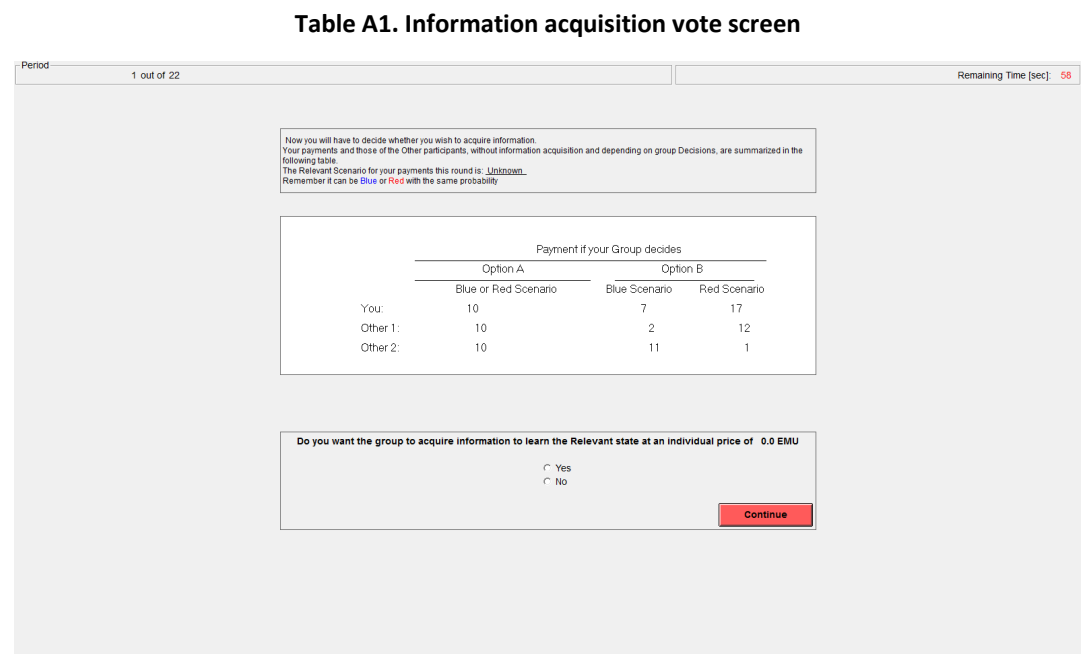

Table A2. Alternative choice vote screen if group DID acquire information

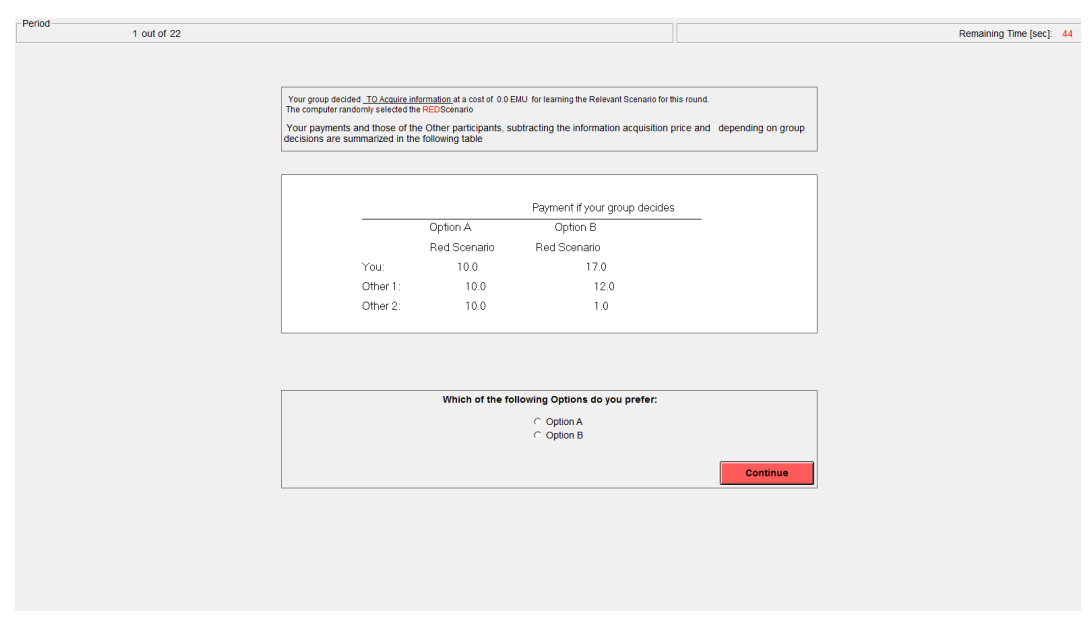


Table A3. Alternative choice vote screen if group DID NOT acquire information

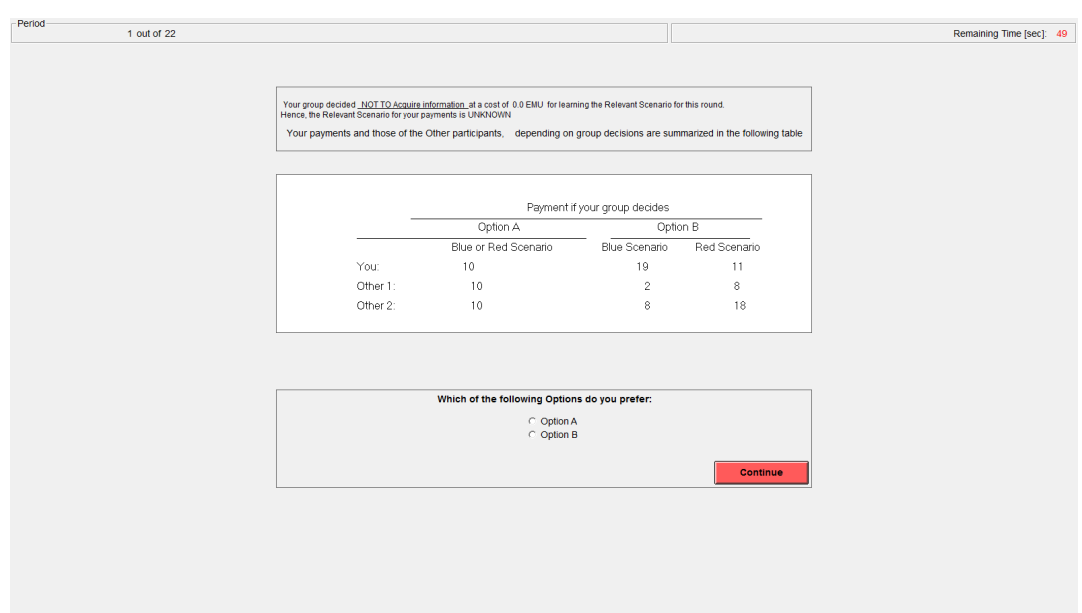

Table A4. Feedback at the end of each period

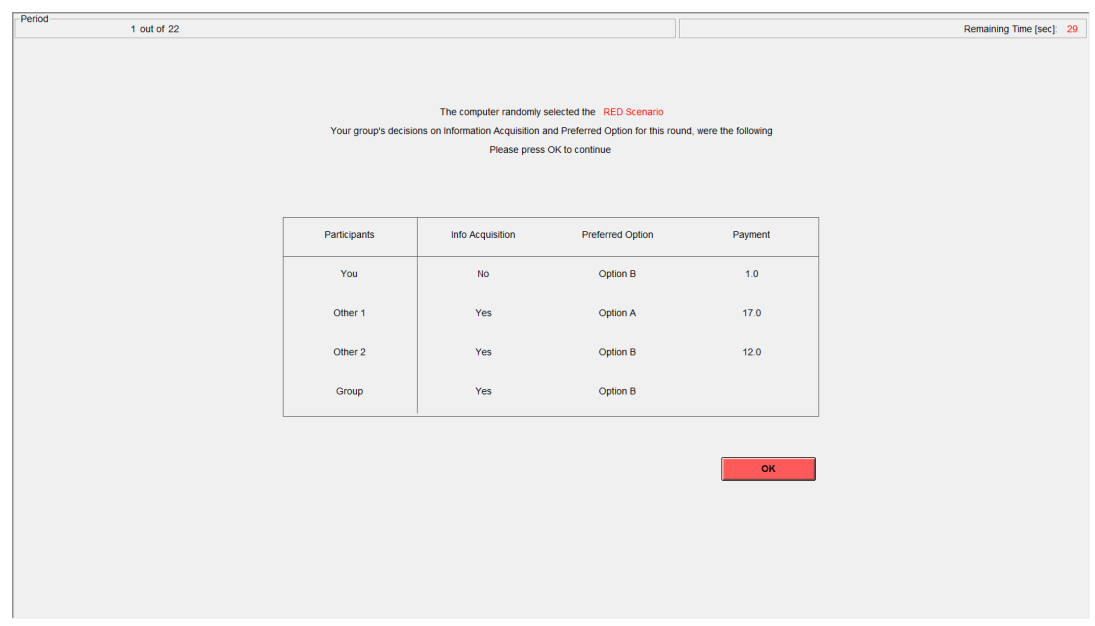


Table A5. Information acquisition vote screen for Order treatment

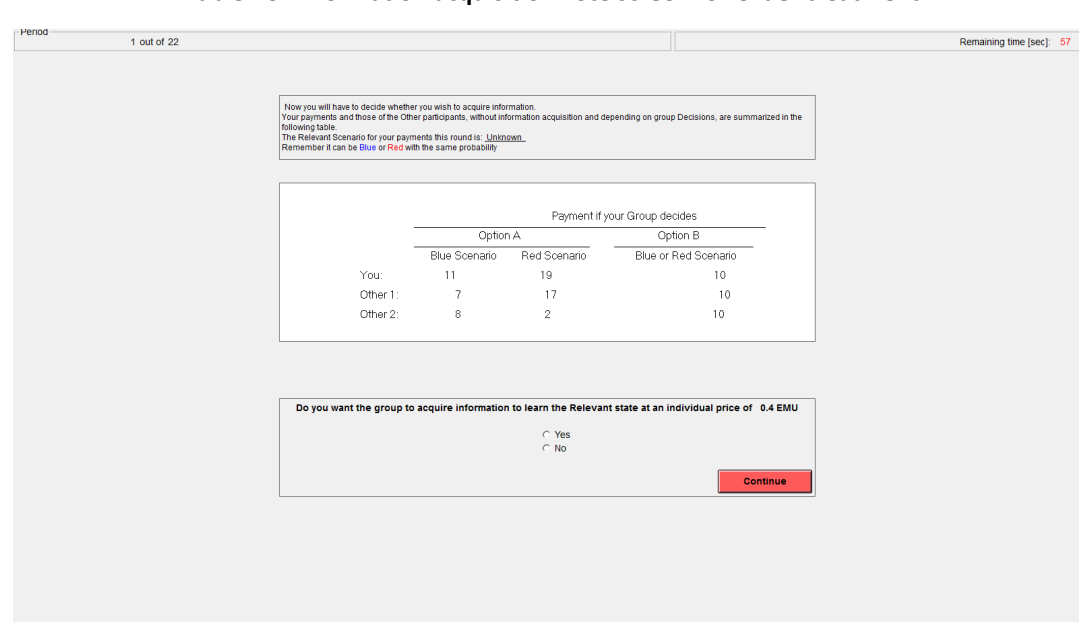

